\title{
1 Performance of CPT-based methods to assess monopile driveability in North Sea sands
}

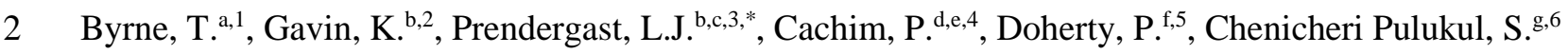

$3 \quad{ }^{\text {a }}$ School of Civil Engineering,

4 University College Dublin,

5 Belfield,

6 Dublin 4,

7 Ireland

8

$9{ }^{\mathrm{b}}$ Faculty of Civil Engineering and Geosciences,

10 Delft University of Technology,

11 Building 23,

12 Stevinweg 1 / PO-box 5048,

132628 CN Delft / 2600 GA Delft,

14 The Netherlands

15

${ }^{\mathrm{c}}$ Department of Civil Engineering,

Faculty of Engineering,

University of Nottingham,

Nottingham,

NG7 2RD,

United Kingdom

${ }^{\mathrm{d}}$ RISCO \& Department of Civil Engineering,

University of Aveiro,

3810-193 Aveiro,

Portugal

${ }^{\mathrm{e}}$ Laboratory of Geotechnics,

Department of Civil Engineering,

University of Ghent,

Belgium

${ }^{\mathrm{f}}$ Gavin and Doherty Geosolutions,

Unit A2,

Nutgrove Office Park,

Rathfarnham,

Dublin 14,

Ireland

${ }^{\mathrm{g}}$ Shell UK Ltd,

1 Altens Farm Road,

Nigg,

Aberdeen,

AB12 3FY,

United Kingdom

46

47

${ }^{*}$ Corresponding author

49 Email: ${ }^{1}$ tiernan.byrne@ucdconnect.ie, ${ }^{2}$ k.g.gavin@tudelft.nl, ${ }^{3}$ luke.prendergast@nottingham.ac.uk, 


\section{Abstract}

Offshore pile driving is a high-risk activity as delays can be financially punitive. Experience of pile driving for offshore jacket structures where pile diameters are typically $<2 \mathrm{~m}$ has led to the development of empirical pile driveability models with proven predictive capability. The application of these methods to larger diameter piles is uncertain. A major component of driveability models involves estimating the static resistance to driving, SRD, a parameter analogous to pile axial capacity. Recent research on axial capacity design has led to improved models that use Cone Penetration Test, CPT data to estimate pile capacity and include for the effects of friction fatigue and soil plugging. The applicability of these methods to estimating pile driveability for larger diameter piles is of interest. In this paper, recent CPT based axial capacity approaches, modified for mobilised base resistance and ageing, are applied to estimating driveability of $4.2 \mathrm{~m}$ diameter piles. A database of pile installation records from North sea installations are used to benchmark the methods. Accounting for factors such as pile ageing and the relatively low displacement mobilised during individual hammer blows improves the quality of prediction of pile driveability for the conditions evaluated in this study.

Keywords: Pile Driveability; Static Capacity; UWA-05; IC-05; Sand; Monopiles; Offshore Wind; Base Resistance-Settlement

\section{Introduction}

The majority of offshore structures, whether conventional oil and gas platforms or wind turbines, are supported by driven open-ended steel piles, used as single, large diameter laterally loaded monopiles or multiple axially loaded piles for a jacket structure. The piles resist both the topside loads and the environmental wind and wave forces (Arany et al., 2017; Prendergast et al., 2018) and efficient installation is critically important to minimise time delays and prevent material damage. Piles are installed using large hammers, which are usually hydraulically powered to provide a controlled driving force. Prior to selecting an appropriate hammer, a driveability analysis is usually performed to ensure the selected equipment is capable of installing the pile to the target depth in a reasonable time-frame and without overstressing the steel pile shaft. This process is essential to the smooth installation of any offshore structure, as driving delays can result in significant financial overspends due to vessel downtime. Premature refusal or structural damage to the piles can also threaten the feasibility of an offshore project. Therefore, a comprehensive driveability analysis should be undertaken that considers the entire driving system including the hammer performance, pile geometry, site specific soil conditions and the soil-structure interaction problem.

The Static Resistance to Driving (SRD) is a profile of shaft and toe resistance developed during pile installation, and an estimate of this is required to perform a driveability study. An SRD profile differs from a static capacity profile in that it models the cumulative increase in shaft capacity with further pile penetration and has a toe resistance associated with each driving increment, as opposed to a static profile with a single base resistance. Moreover they differ in terms of time, degree of mobilisation and consolidation. Accurately predicting the soil-structure interaction is critical to the driveability process and is arguably the most challenging aspect (Prendergast and Gavin, 2016; Wu et al., 2018). Traditional approaches for predicting SRD such as Stevens et al. (1982), Toolan and Fox (1977), and Semple and Gemeinhardt (1981) are largely empirical and therefore, extrapolation to pile geometries and soil conditions outside of the dataset on which they are based is highly questionable. The application of such 
methods in the extreme hard tills or very dense sands (where the CPT end resistance $\mathrm{q}_{\mathrm{c}}$ value is typically in the range $30-100 \mathrm{MPa}$ ) in the North Sea and for the large diameter monopiles supporting wind turbines should be assessed. Aldridge et al. (2010) highlights the difficulties in predicting the installation resistance of $2.6 \mathrm{~m}$ diameter piles at the Clair platform in the North Sea, west of the Shetlands, where the undrained shear strength of the underlying glacial till exceeded $2500 \mathrm{kPa}$. In this instance, a series of pile driving trials were conducted in advance of the platform installation to ensure the piles could reach the target depth. Predictions based on the IC-05 (Jardine et al., 2005) methodology which accounts for high strength of the clay, the pile geometry, group effects and cyclic loading provided much more consistent estimates of the pile resistance than standard offshore methods.

Schneider and Harmon (2010) proposed a pile driveability model based on the UWA-05 (Lehane et al., 2005) method that incorporates friction fatigue and accounts for the effects of pile plugging. They note that inertial effects during driving mean that the soil plug remains at or near the sea bed level during installation. As a result they propose a methodology in which the base resistance develops only on the pile annulus, and the shaft resistance develops both on the external pile surface and internally on the pile plug. They suggest that the stress on the pile annulus be taken as $35 \%$ of the CPT $\mathrm{q}_{\mathrm{c}}$ value at the pile tip and the shear resistance mobilised by the soil plug is $50 \%$ of the external shear resistance. They found this approach gave consistent predictions of driving resistance for four, open-ended pipe piles driven with diameters ranging from $0.356 \mathrm{~m}$ to $2 \mathrm{~m}$ at three sites, in Japan, USA and the Netherlands.

Byrne et al. (2012) examined the ability of commonly employed pile driveability models (Semple and Gemeinhardt, 1981; Stevens et al., 1982; Toolan and Fox, 1977) to predict the installation response of a $0.762 \mathrm{~m}$ diameter skirt pile and a $4.2 \mathrm{~m}$ diameter monopile installed in dense North Sea sand. Somewhat surprisingly the models provided poorest predictions of the installation response of the $0.762 \mathrm{~m}$ pile with the range of measured to predicted blow-counts varying from $30 \%$ to $180 \%$ at the final penetration depth of $34 \mathrm{~m}$. The methods provided much closer estimates for the $4.2 \mathrm{~m}$ diameter pile at the final penetration depth of $31.5 \mathrm{~m}$ (estimates in the range $55 \%$ to $135 \%$ ). However, for shallow penetrations of the monopile the variance was much larger and methods which under-predicted the blow-counts for shallow penetrations, tended to over-estimate the resistance at depth and vice-versa. This suggests some fundamental inherent bias in the models which would lead to inconsistent estimates of the full pile driving process.

In this paper, records from a number of pile installations in the North Sea are used to compare the performance of conventional driveability analyses and new CPT approaches modified to account for important processes including pile ageing, friction fatigue, low base displacement and plugging (Gavin and Lehane, 2007). The pile driving data from six sites, namely Caravel, Cutter, Shamrock, L09FA1, L09FB1 and Skiff are used to compare the predictive performance of the models. The Skiff platform is supported on a jacket with $0.762 \mathrm{~m}$ diameter piles, whilst the remaining platforms are founded on single, $4.2 \mathrm{~m}$ monopiles. The limitations and biases of each driveability method are assessed and recommendations are made for a more accurate scientific approach.

\section{Modelling Process}

Determining the optimum pile geometry is an iterative process, where the trade-off between the higher capacities achieved using larger piles is offset by the increased difficulty and risk associated with driving these piles to the desired penetration. A flow-chart describing the principal inputs required and the analysis procedure used to conduct a driveability study is shown in Fig. 1. The three main inputs are the soil parameters, pile properties and hammer details. The pile properties and hammer 
140 characteristics are relatively well understood and can be determined with a reasonable degree of 141 accuracy. Given the difficulties in sampling and testing offshore soils in-situ Cone Penetration Testing 142 (CPT) is widely undertaken for offshore projects with most installations having at least one complete 143 CPT profile. Given the similarities between CPT and pile installation, many correlations have been 144 developed linking pile end, $\mathrm{q}_{\mathrm{b}}$ and shaft resistance, $\mathrm{q}_{\mathrm{s}}$ to the CPT end resistance, $\mathrm{q}_{\mathrm{c}}$ which usually give 145 better predictions of pile response than approaches which use soil parameters within an effective stress 146 framework (Jardine et al., 2005). The main output of interest for this paper is a prediction of the blow147 counts required to drive a given pile, as this will be compared to the real blow-counts across the 148 investigated sites. It should be noted that there is potential for several combinations of the input 149 parameters to yield similar output values. The SRD profiles in this paper are derived using measured 150 CPT profiles as input. To ensure that the modelling is as accurate as possible, information from the monitoring reports related to hammer type, input energy, driving delays, etc. for each pile is carefully considered in each driveability analysis to ensure the predictions for each proposed soil resistance are genuine.

Fig. 1. Flow-chart of principal inputs and outputs available from a wave equation based driveability analysis.

The total resistance of a pile to driving results from a combination of the static SRD, dynamic increases in pile capacity due to inertial effects and increases in capacity due to viscous rate effects. Driveability methods used to derive the static SRD are discussed in Section 3. The remaining effects (inertia, viscous rate effects) are accounted for within the wave equation analysis problem. In this paper, a commercially available finite-difference software GRLWEAP Off-Shore 2010 (Pile Dynamics, 2010) was used to perform the operations and analyse the energy transferred to the pile from each hammer blow. GRLWEAP is a 1-D wave equation analysis software capable of simulating the response of a pile to pile driving equipment, and is fundamentally based on solving the wave equation shown in Eq. (1)

$$
\rho\left(\frac{\delta^{2} \mathrm{u}}{\delta \mathrm{t}^{2}}\right)=E\left(\frac{\delta^{2} \mathrm{u}}{\delta \mathrm{x}^{2}}\right)
$$

where $\rho$ is the mass density $\left(\mathrm{kg} / \mathrm{m}^{3}\right), E$ is the elastic modulus $\left(\mathrm{N} / \mathrm{m}^{2}\right)$. The wave speed, $\mathrm{c}$ is a function of the mass density and elasticity as follows, $c=\sqrt{\frac{E}{\rho}}$.

GRLWEAP has a number of inbuilt static SRD models, however, it also allows the user manually input shaft and end resistance profiles, thus making it ideal for the problem in this paper. The dynamic forces and viscous rate effects are represented by damping values, which vary according to soil type. It is usual for an SRD model to be used with an accompanying set of standard damping values. Also specified are quake values, the displacement required to achieve yield, see Fig. 2. The parameters used in this study are presented in Table 1 and are derived from original references, where possible. 
Table 1. Quake and damping values.

180

181

182

183

184

185

186

187

188

189

190

191

192

193

194

195

196

197

198

199

200

201

202

203

204

GRLWEAP has an extensive archive of hammer types with a database of their properties (such as hammer masses and drop heights, among other properties). Monitoring reports from each of the installations considered in this paper included details of events such as delays occurring during driving, thereby allowing the hammer performance/efficiency and driving system to be modelled accurately. With the exception of the monopile at Cutter, each pile was dynamically monitored which enabled the pile enthru energy (energy that the pile experiences) to be calculated and replicated in the analysis. Hammer stroke heights were adjusted during the modelling process so that the output energies matched the recorded values. Standard efficiencies were applied based on suggested values for each hammer.

The friction fatigue effect, whereby shear resistance in a given layer reduces as the pile tip advances is included in the later SRD models, usually by means of including a degradation term in the calculation of the shear stresses of the form $(h / R)^{\mathrm{n}}$ where $h$ is the vertical distance from the pile tip to the soil horizon in question and $R$ is the pile radius, see Fig. 3.

Fig. 3. Definition of (h/R) expression.

Because the term causes the shape of the shear resistance distribution to change with pile penetration, some averaging technique is necessary. Schneider and Harmon (2010) found that the shape of the shaft friction distribution had a negligible effect on the resultant bearing graph. They suggest the change in shaft capacity between two successive depth increments be used to calculate the pseudo average shaft friction $\left(\Delta \tau_{f, \text { avg }}\right)$, as shown in Eq.(2).

$$
\Delta \tau_{f, \text { avg }}=\frac{\sum Q_{S, L}-\sum Q_{S, L-1}}{\pi D \Delta L}
$$

where $\sum Q_{S, L}$ is the cumulative shaft resistance at a given tip depth; $\sum Q_{S, L-1}$ is the cumulative shaft resistance at the previous depth increment; $\Delta L$ is the depth increment; and $D$ is the pile diameter. This pseudo averaging technique was applied to the relevant models incorporating friction fatigue in the present analysis.

\section{Traditional Static Resistance to Driving (SRD) approaches}

Numerous driveability approaches have been proposed throughout the years to calculate the soil static resistance to driving and are still frequently used in North Sea pile design. The initial methods were developed in the late 1970's and early 1980's. Three traditional driveability models were employed in the analysis in this paper.

\subsection{Toolan \& Fox (1977)}

The Toolan and Fox model proposes the calculation of the unit toe resistance, for both cohesive and cohesionless soil, as a weighted average of the cone tip resistance $\left(\mathrm{q}_{\mathrm{c}}\right)$ over a number of pile diameters above and below the pile tip. The unit skin friction in sands can be determined as a fraction of the 
recorded cone resistance, (1/300 for a dense sand) or alternatively may be computed in accordance with the American Petroleum Institute (API) (API, 2007) guidelines, and is limited to $120 \mathrm{kPa}$. For a fully coring pile, unit skin friction is applied to the internal and external shaft area equally while the unit toe resistance is applied to the pile annulus.

\subsection{Stevens et al. (1982)}

For cohesionless materials, both unit toe and skin resistances are calculated using the standard static capacity procedures outlined in the API method (API, 2007). Limiting input values of unit skin and toe resistance are assigned while the model defines lower (LB) and upper bound (UB) static predictions for plugged and coring conditions. Large open-ended pipe piles, similar to those installed at the six locations considered in this paper, usually remain fully coring during pile installation (internal soil core level approximately at external sea bed level). The lower bound case adopts an internal shaft friction half that of the exterior, with the upper bound assuming that both are equal. The unit skin friction is first calculated from the API method (API, 2007) and adjusted incrementally by a capacity factor determined empirically from wave equation analysis.

\subsection{Alm \& Hamre (2001)}

The original Alm and Hamre (1998) model was developed from back-calculated driveability studies from North Sea installations. An updated version presented in 2001 moved to a CPT based approach to address issues with variability and uncertainty in selection of soil parameters. The model benefited from an enlarged database containing longer and larger $(1.8-2.7 \mathrm{~m})$ diameter piles and incorporated the friction fatigue effect.

The ultimate shaft friction, $\tau_{\mathrm{f}}$ is given by Eq.(3).

$$
\tau_{f}=\tau_{r e s}+\left(\tau_{f \max }-\tau_{r e s}\right) e^{-k h}
$$

$$
\tau_{f \max }=0.0132 q_{c}\left(\frac{\sigma_{v 0}^{\prime}}{P_{a t m}}\right)^{0.13} \tan \delta
$$

$$
k=0.0125\left(\frac{q_{c}}{P_{a t m}}\right)^{0.5}
$$

Where: $\tau_{\text {fmax }}$ is the peak shaft friction, $\tau_{\text {res }}$ is the residual friction $\left(=0.2 \tau_{\text {fmax }}\right), \mathrm{h}$ is the depth of the layer from the pile tip, $\mathrm{k}$ is a shape factor and $\delta$ is the interface friction angle. The unit end bearing resistance, $\mathrm{q}_{\mathrm{b}}$ is given by Eq. (4).

$$
q_{b}=0.15 q_{c}\left(\frac{q_{c}}{\sigma_{v 0}^{\prime}}\right)^{0.2}
$$

\section{Application of axial static capacity approaches to driveability}

The CPT based design methods for calculating the axial static resistance of piles in sand known as the IC-05 and UWA-05 methods drew heavily on the findings from highly-instrumented model pile tests undertaken by a number of researchers at Imperial College London (Jardine et al., 2005; Lehane et al., 2005). In particular these tests provided new insights into the mechanisms controlling the development 
of shaft friction for displacement piles in sand. The IC-05 method for estimating the ultimate shaft resistance is shown in Eq.(5).

$$
\tau_{f}=a\left[0.029 \cdot b \cdot q_{c}\left(\frac{\sigma_{v 0}^{\prime}}{p_{r e f}}\right)^{0.13}\left[\max \left(\frac{h}{R^{*}}, 8\right)\right]^{-0.38}+\Delta \sigma_{r d}^{\prime}\right] \tan \delta_{f}
$$

Where $\mathrm{a}=0.9$ for open-ended piles, $\mathrm{b}=1.0$ for piles in compression, $\mathrm{R}^{*}$ is the equivalent radius of $\mathrm{a}$ closed-ended pile (assuming no plugging occurs during installation) and $\Delta \sigma^{\prime}{ }_{r d}$ is the change in radial stress due to interface dilation. This term can be ignored for offshore piles.

The unit base resistance is given by Eq.(6).

$$
\frac{q_{b}}{q_{c}}=\left(0.5-0.25 \log \frac{D}{D_{C P T}}\right)
$$

Where: $\mathrm{D}_{\mathrm{CPT}}$ is the diameter of the CPT penetrometer.

The UWA-05 method has a similar formulation for shaft resistance as shown in Eq. (7).

$$
\tau_{f}=\frac{f_{t}}{f_{c}}\left[0.03 \cdot q_{c} \cdot A_{r . e f f} 0.3\left[\max \left(\frac{h}{D}, 2\right)\right]^{-0.5}+\Delta \sigma_{r d}^{\prime}\right] \tan \delta_{f}
$$

Where: $\frac{f_{t}}{f_{c}}=1$ for compression and 0.75 for tension. The effective area ratio, $A_{r, e f f}=1-\operatorname{IFR}\left(\frac{D_{i}}{D}\right)^{2}, \mathrm{D}$ and $D_{i}$ are the external and the internal diameter of the pile respectively. IFR is the incremental filling ratio (or change in soil plug length for an increment of pile penetration).

The unit base resistance is calculated using the expression in Eq.(8).

$$
\mathrm{q}_{\mathrm{b} 0.1} / \mathrm{q}_{\mathrm{c}, \mathrm{avg}}=0.15+0.45 \mathrm{~A}_{\mathrm{r}, \mathrm{eff}}
$$

While not explicitly designed for determining a soil SRD, similarities between the mechanisms controlling installation resistance and static capacity suggest that with modification and adaptation these methods could prove appropriate for use in driveability analyses. A case study presented by Overy and Sayer (2007) indicated that the IC-05 method gave reasonable predictions for drill-drive operations of the main conductor piles at the same Skiff site considered in this study.

In this paper the possible contribution of four factors that could differentiate the installation and static loading processes are considered:

(i) The phenomenon of pile ageing (capacity increase with time after installation) is becoming more widely accepted. The recent CPT based design methods are calibrated using load tests performed generally 10 to 30 days after installation. Therefore, the pile resistance during installation will be lower than the models suggest.

(ii) Given the relatively low displacements experienced during individual hammer blows the rate of pile base mobilisation is considered explicitly. 
297 The behaviour of the soil plug during installation and under static loading can differ substantially. Due to inertial effects during driving the internal soil plug resistance is low and large diameter piles usually remain near fully coring (the soil plug moves inside the pile at a similar rate to the pile penetration). In SRD and static capacity models two failure conditions are considered, for static loading: (i) a plugged failure occurs when the soil beneath the pile tip displaces and the inner column of soil remains in contact with the inner pile surface, advancing with the downward moving pile under failure, in effect almost akin to a closed ended pile, (ii) an unplugged failure, where the internal soil cylinder remains stationary as the pile progresses. In reality, both mechanisms may take place during failure.

The IC-05 method has a procedure and guidance to predict whether plugged or unplugged failure develops. In the instance of unplugged failure (which was the mode of failure predicted for all piles in this study) the full CPT resistance is applied over the annular base area only and the plug resistance (internal shaft friction) is not taken into account explicitly. For the UWA-05 model, the plug is presumed not to fail during static loading and a modified unit base resistance (which considers the effective area ratio and accounts directly for the degree of plugging during installation) acts over the gross pile area. This takes into consideration the reduced base stiffness developed during coring installation of the pile. While these may provide accurate static capacity estimates, it may not model or represent the interaction between the pile and soil plug during driving, as noted by Overy and Sayer (2007) for North Sea pile installations.

The base capacity evaluated from the IC-05 and UWA-05 models assume pile tip displacements $\left(\mathrm{w}_{\mathrm{b}}\right)$ of $10 \%$ of the pile diameter (D), as the failure criteria. During driving, the pile penetration per blow is much lower than this value and a reduction factor should be applied to account for this effect. A threestage base resistance-settlement model, proposed by Gavin and Lehane (2007), is implemented as a means of estimating the base resistance mobilised during each hammer impact. The model, schematically presented in Fig. 4, considers the pile tip displacement $\left(\mathrm{w}_{\mathrm{b}}\right)$, normalised by the pile diameter $(D)$, and plotted against the mobilised base resistance $\left(\mathrm{q}_{\mathrm{b}}\right)$.

Fig. 4. Base resistance-settlement model (Gavin and Lehane, 2007)

The base resistance-settlement model considers the initial settlement response to be linear until a yield strain $\left(\mathrm{w}_{\text {by }} / \mathrm{D}\right)$ is reached (assumed to occur at $1.5 \%$ of pile diameter), followed by a non-linear parabolic stage to a strain at $10 \%$ of pile diameter (i.e. $\mathrm{w}_{\mathrm{b}} / \mathrm{D}$ of 0.1$)$. The linear stage $\left(\mathrm{w}_{\mathrm{b}} / \mathrm{D}<\mathrm{w}_{\mathrm{by}} / \mathrm{D}\right)$ is governed by the small strain soil elastic stiffness $\left(\mathrm{E}_{0}\right)$. While $\mathrm{E}_{0}$ should be computed from shear wave velocity measurements based on seismic cone or bender element tests, in practice, these may not be available and it can be approximated using correlations with CPT q data (Prendergast et al., 2013), such as those reported by Robertson (1990) and Schnaid et al. (2004). The linear portion of the curve can be represented by Eq.(9).

$$
\begin{aligned}
& q_{b}=\left[k\left(\frac{w_{b}}{D}\right)\right]+q_{b, r e s} \\
& k=\left(\frac{4}{\pi}\right)\left[\frac{E_{0}}{1-v^{2}}\right]
\end{aligned}
$$


where $v$ is the Poisson's ratio. The parabolic portion ( $\left.\mathrm{w}_{\mathrm{by}} / \mathrm{D}<\mathrm{w}_{\mathrm{b}} / \mathrm{D}<0.1\right)$ is given in Eq. (10):

$$
q_{b}=\left[k\left(\frac{w_{b y}}{D}\right)^{1-n}\left(\frac{w_{b}}{D}\right)^{n}\right]+q_{b, r e s}
$$

The residual base stresses ( $\mathrm{q}_{\mathrm{b}, \mathrm{res}}$ ) associated with previous hammer blows may be of the order of $1 \%$ to $10 \%$ of the CPT $\mathrm{q}_{\mathrm{c}}$ value at a given depth and the sensitivity of the analysis to a range of potential residual stress conditions is assessed in this paper. The base-settlement model was implemented as a modified form of the UWA- 05 approach with the $\mathrm{w}_{\mathrm{b}} / \mathrm{D}$ ratio being estimated based on a typical displacements recorded for piles installed at the sites considered.

\section{Pile Database}

The installation database assembled by Shell UK was interrogated and the results from the installation of five monopiles were selected for analysis. These monopiles are $4.2 \mathrm{~m}$ diameter steel open ended piles installed at Caravel, Shamrock, L09FA1, L09FB1 and Cutter, respectively. In addition, a 0.762m diameter skirt pile supporting a jacket structure at the Skiff site was also analysed for comparative purposes. The locations of each of the installations are shown in Fig. 5 and Table 2. The piles were predominantly driven in medium dense $(\approx 40 \%$ overall) to dense sand $(\approx 20 \%)$ with frequent very dense zones $(\approx 30 \%)$. There were instances of loose to very loose sand $(<10 \%)$ and layers and bands of clay were occasionally present.

Fig. 5. Location map showing pile locations off Dutch and UK coasts.

Table 2 compares the primary geotechnical properties at each site and provides other relevant information such as results from laboratory tests conducted during the site investigation. The sites are broadly similar with some expected variation in sand relative densities and CPT $\mathrm{q}_{\mathrm{c}}$ profiles at given depths.

Soil plug measurements were recorded at sea bed level for Cutter after driving ceased and although no soil plug measurements were made at the remaining sites, the monopiles would most likely have been fully coring. It is also reasonable to assume that the Skiff skirt pile would be coring (or partially plugged), according to IC-05 plugging guidelines.

\section{Table 2. Site Description.}

Geotechnical logs, in addition to in-situ and laboratory test reports, were available for each location and provided a comprehensive catalogue of the site conditions from which soil profiles could be derived. Relative densities were evaluated by interpreting the CPT cone resistance based on the relationship proposed by Jamiolkowski et al. (1988) shown in Eq. (11). 


$$
D_{r}=100\left[\frac{1}{2.93} \ln \frac{q_{c}}{205 \sigma_{m}^{\prime}{ }^{0.51}}\right]
$$

where $D_{r}$ is the estimated relative density $(\%), q_{c}$ is the measured cone resistance $(k P a), \sigma_{m}^{\prime}$ is the estimated mean effective stress at the test depth $(\mathrm{kPa})$ and

$$
\sigma_{m}^{\prime}=\left[\frac{p_{0}{ }^{\prime}\left(1+2 K_{0}\right)}{3}\right]
$$

where $\mathrm{p}_{0}$ ' is the effective overburden pressure $(\mathrm{kPa})$ and $\mathrm{K}_{0}$ is the coefficient of lateral earth pressure. Tentative upper and lower bound values of $\mathrm{K}_{0}$ were used to estimate the relative density profiles which are illustrated in Fig. 6 and are accompanied by the corresponding CPT q profiles from each site. The consistency of the sand can be categorised according to the ranges of relative densities proposed by Lambe and Whitman (1969) as presented in Table 3.

Table 3. Relative Density $\left(\mathrm{D}_{\mathrm{r}}\right)$ definitions (Lambe and Whitman, 1969)

When the $D_{r}$ traces abruptly return to zero percent, this indicates the transition from a sand layer to a clay layer and likewise, where the relative density spikes sharply from zero, this indicates the return to a sand layer. The resistance of stiff-hard clays to an advancing CPT cone is usually less than that of medium dense to dense sand and it would be expected that the measured total cone resistance in clay would be noticeably less than that of the sand. In this way, the two traces should mimic each other at the interface zones between clay and sand. This is mostly true for the sites in Fig. 6. Each $0.5 \mathrm{~m}$ depth increment used in the calculation of the respective methods' SRDs had an associated CPT q value. A simplified profile (ignoring the extremes in CPT $\mathrm{q}_{\mathrm{c}}$ ) was not assumed as this would be un-conservative because of the potential to underestimate the soil strength. Instead, values close to the actual CPT $\mathrm{q}_{\mathrm{c}}$ traces were assigned in each case.

Fig. 6. Site CPT $q_{c}$ and Relative Density $\left(D_{r}\right)$ Profiles.

\section{Results}

In this section, the results are presented as the application of the various methods to the driveability problem, namely traditional approaches (section 6.1), static capacity approaches (section 6.2) and modified static capacity approaches (section 6.3). The performance of the various approaches to analysing monopile driveability is critically evaluated and discussed.

\subsection{Traditional driveability approaches}

The pile installation performance was predicted by performing wave equation analyses using the driveability software. Having entered the pile properties and SRD profiles the driving process was simulated by adjusting hammer stroke heights and a profile of blow-counts with depth was predicted. Blow count profiles with depth from two of the six sites considered namely; Skiff (pile diameter $0.762 \mathrm{~m}$ ) and Caravel (pile diameter $4.2 \mathrm{~m}$ ) are shown in Fig. 7. These types of plot are frequently produced during the pile design phase to determine if excessive blows would be required to drive a pile. It is common in practice to have best and upper estimates. Usually, a nominal number of 250 blows per $0.25 \mathrm{~m}$ penetration is defined as pile refusal, however, this limit can be substantially lower for large 
419 diameter monopiles, due to the increased risk of damage associated with the use of larger hammers 420 required to drive the piles. It is evident in Fig. 7(a) that a number of the approaches predicted more than 421250 blows $/ 0.25 \mathrm{~m}$ were required to drive the piles at Skiff.

422 For example the upper bound estimates for the established approaches of Stevens et al. which assumes the pile is plugged predicts refusal at $27.5 \mathrm{~m}$. In reality the pile was installed in a partially plugged mode and Stevens et al. (1982) recommend using the Plugged Lower Bound (Steve Plug LB) prediction as a best estimate for piles in dense sands, even for piles which have a high probability of coring during installation. The lower bound line here is in reasonably good agreement with the measured blow counts, albeit underestimating the pile resistance for pile penetrations in excess of $25 \mathrm{~m}$. In contrast, when this method was applied to the large diameter monopile, refusal was predicted within the first few metres of penetration. A similar trend was noted for all the monopiles considered. The Stevens approach was developed using a dataset of installations consisting mainly of piles of less than $2 \mathrm{~m}$ in diameter, typically used during the 1970's and 1980's. While the approach provides an acceptable estimate here for the $0.762 \mathrm{~m}$ diameter skirt pile at Skiff it is totally inadequate for the monopiles, where refusal was almost immediate. This highlights the potential pitfalls in extrapolating existing methods to piles of larger diameters.

Although the Toolan \& Fox (T\&F) and Alm \& Hamre Upper Bound (A\&H UB) both predicted early refusal for the pile at Skiff, they return to within acceptable limits at deeper penetrations. It is at the engineer's discretion and best judgement must be used in deciding whether these periods of perceived hard driving would be acceptable during the course of a driveability study, considering that it is the upper bound estimate of Alm \& Hamre that predicts this. The best estimate (A\&H Best) falls comfortably below 250 blows $/ 0.25 \mathrm{~m}$ penetration.

For the methods that assume the pile is coring through installation, e.g. Stevens et al. (Stevens Cored LB \& UB), the predicted blow counts increased steadily with penetration for both the Skiff and Caravel piles and were not overly sensitive to abrupt changes in soil profile. The estimates tend to under predict the recorded blow counts at each site. It is somewhat unexpected to see the high degree of variation in the predictions for Skiff in comparison to the relatively narrow band produced at Caravel, excluding the Stevens plugged estimates. It is worth noting that the soil profile at Skiff has a much higher proportion of dense to very dense sand over the embedded pile length that may influence the disparity in the predictions. Table 4 shows the total blow-counts required to drive the piles as estimated from each method, for both Skiff and Caravel.

In addition to comparing blow counts it is important to consider both the driving stresses and installation time to ensure that the pile is not damaged and the installation costs are not excessive. This is particularly important for wind farm sites where a large number of piles need to be driven. While neither of these aspects were explicitly considered in the present study, it is noteworthy that moderately 
high but acceptable driving stresses can become an issue with fatigue damage, if prolonged periods of high blow counts are expected, so an indirect measure of this is provided.

\subsection{Unmodified static capacity approaches}

In this section, the application of more recently developed CPT-based static (axial) capacity approaches to estimating driveability is investigated. The IC-05 and UWA-05 static capacity methods are first applied in their raw (unmodified) form to estimate driveability, by deriving SRD profiles for the shaft and toe resistance based on each method (Jardine et al., 2005; Lehane et al., 2005). The friction fatigue effect, which results in the distribution of shaft friction varying with advancing pile tip, is incorporated by calculating the pseudo-average shaft friction between adjacent depths, see Eq. (2). The results of the driveability analysis for the six sites derived using the IC-05 and UWA-05 and compared to the recorded blow counts are shown in Fig. 8 .

Fig. 8. Blow counts/ $0.25 \mathrm{~m}$ for all sites with unmodified CPT-based static capacity approaches

From the results in Fig. 8, it can be observed that for Skiff, Caravel, Cutter and Shamrock, both methods broadly over-predict the blow counts required to install each pile. For Caravel and Shamrock, the IC05 method provides a reasonable estimate of the driveability with some significant over-prediction in places (e.g. Caravel upper layers). However, for L09FA1 and L09FB1, the IC-05 approach tends to under-predict somewhat. The relatively poor predictive resistance of these methods in their unmodified form is unsurprising as they were developed to predict the medium-term (10 to 30 day following installation) static capacity of piles. Moreover, the base resistance calculated from the IC-05 and UWA05 approaches assumes a base displacement of 0.1D is mobilised. Nonetheless, the methods appear to provide reasonable profiles on the driveability resistance (mirroring the blow counts in the different layers) and therefore the next section considers some modifications that could be applied to the methods to simulate the actual driving process more closely.

\subsection{Modified static capacity approaches}

The IC-05 and UWA-05 static capacity methods are modified in this section and applied to estimating driveability. In the first instance, to account for the fact that pile ageing effects are inherently considered in the static capacity approaches, the shaft capacity as derived by each method is reduced to $70 \%$ of the unmodified value. The reduction factor of 0.7 for short-term shaft capacity was chosen based on the interpretation by Jardine et al. (2006) of Intact Ageing Curves from pile tests that investigated the ageing characteristics of piles installed in dense sand at Dunkirk. Based on static and dynamic load tests, the authors proposed that the end of driving shaft capacity of piles was $70 \%$ of the resistance predicted using the ICP design method. This proposal was consistent with field tests reported by Gavin et al. (2013) and Karlsrud et al. (2014) summarised in Gavin et al. (2015). For the UWA-05 approach, the base resistance is further modified herein using the base-settlement model in Fig. 4. In this modification, a revised base resistance is calculated using the actual settlement under each hammer blow (averaged into layers) and normalized to the pile diameter in each case. The new base resistance is calculated using Eq. (9), initially assuming no residual base resistance ( $\left.\mathrm{q}_{\mathrm{b}, \mathrm{res}}\right)$ acts on the system. The results of the modified approaches with the actual measured blow counts are shown in Fig. 9.

Fig. 9. Blow counts/ $0.25 \mathrm{~m}$ for all sites with modified CPT-based static capacity approaches 
In Fig. 9, a more reasonable prediction of blow counts is achieved in each case. The UWA approach predicts a significantly lower blow count vs penetration than the unmodified approach in Fig. 8. Broadly speaking, it now under predicts the blow counts for each pile. The IC-05 approach both over and under predicts the blow-counts across the sites, though generally speaking provides a reasonable estimate in most cases. This approach under-predicts the response at the L09FA1 and L09FB1 sites. The blowcounts in the upper layers of the Cutter site are heavily over predicted. This is a result of the estimated w/D under each hammer blow in the upper layers being over-predicted due to the lack of actual blow count information for these depths (an average was assumed based on the initial blow-count information). Therefore, the results for Cutter in the upper layers are not a realistic estimate of the actual behaviour and can be ignored. Results from the Cutter site are less reliable overall due to a failure of the logging system reading the blows for depths larger than $17 \mathrm{~m} \mathrm{bgl}$, as can be seen by the stepped nature of the data signal.

The modified UWA approach provides a reasonably consistent under prediction of blow counts across all sites. As the base resistance was developed using the resistance-settlement model in Fig. 4, and the presence of potential residual base stress after each hammer blow is initially ignored, it is reasonable to account for the presence of potential residual base stress adding to the overall resistance properties. The impact of residual loads on piles in sand is well known however, measurements of residual loads on open-ended piles are rare. Paik et al. (2003) report residual loads measured on $356 \mathrm{~mm}$ diameter closed and open-ended piles installed in dense sand. They found that the residual stress ( $\mathrm{q}_{\mathrm{b}, \mathrm{res}}$ ) normalised by $\mathrm{q}_{\mathrm{c}}$ was similar for both piles (in the range $11 \%$ to $14 \%$ of $\mathrm{q}_{\mathrm{c}}$ ) despite the open-ended pile being nearly fully coring, with a final incremental filling ratio (IFR) of $\approx 78 \%$. Kirwan (2015) reports residual load measurements on a $340 \mathrm{~mm}$ diameter open-ended pile installed in dense sand. The residual load appeared to be affected by the IFR with a ratio $\mathrm{q}_{\mathrm{b}, \mathrm{res}} / \mathrm{q}_{\mathrm{c}}$ of $27 \%$ at the end of installation when the IFR was $40 \%$. Residual base stresses varying from $1 \%$ of the CPT $\mathrm{q}_{\mathrm{c}}$ tip resistance to $10 \% \mathrm{q}_{\mathrm{c}}$ are assumed in a parameter study, conducted herein.

The modified toe resistance from the UWA approach was calculated using the linear portion of the base-resistance settlement model from the actual settlement per blow information from each site averaged into layers. In order to investigate the effect of residual base stresses potentially existing after each hammer blow, residual stresses of $\alpha \mathrm{q}_{\mathrm{c}}$ where $\alpha=\left\{\begin{array}{lllll}0.01 & 0.02 & 0.05 & 0.08 & 0.1\end{array}\right\}^{T}$ were added to the modified toe resistance profile for each site. The resistance was added in a step-wise approach and only added once there was sufficient negative skin friction present at a given depth to resist the residual stress (i.e. the pile was in equilibrium after each hammer blow). The negative skin friction in tension was assumed to be $80 \%$ of the compression resistance. The derived modified toe resistance SRD profiles with step-wise residual stresses and the predicted blow counts for the Caravel site are shown in Fig. 10.

Fig. 10. Effect of residual base stress at Caravel site, (a) UWA modified to resistance with varying residual stresses added, (b) Predicted blow counts for a range of residual added stresses

Fig. 10(a) shows the derived modified UWA-05 toe resistance SRD profiles for Caravel with step-wise residual base stress added in increments corresponding to $0.01 \mathrm{q}_{\mathrm{c}}, 0.02 \mathrm{q}_{\mathrm{c}}, 0.05 \mathrm{q}_{\mathrm{c}}, 0.08 \mathrm{q}_{\mathrm{c}}$ and $0.1 \mathrm{q}_{\mathrm{c}}$ at each depth. Fig. 10(b) shows the blow count predictions for the various input profiles. The recorded blow counts are also shown on the plot. A reasonable match to the recorded profile is obtained with the step-wise residual stress added up to $10 \%$ of the $\mathrm{q}_{\mathrm{c}}$ profile. For the remaining sites, the results of a 
similar analysis are summarised herein. Adding the residual stress component leads to a reasonable prediction for Cutter (though recorded values are albeit somewhat unreliable due to logger failure) as well as for the $0.762 \mathrm{~m}$ pile at Skiff. The UWA modified approach with added residual stress still leads to an under prediction for L09FA1, L09FB1 and Shamrock sites.

The modified IC-05 method previously only considered a reduction in the shaft friction during driving to remove the ageing effect with the toe resistance remaining unmodified. This approach provided a reasonable estimate of the blow counts for the Shamrock site, see Fig. 9(c). A brief analysis is conducted herein to investigate the effect of adopting the UWA-05 modified base resistance with the IC-05 modified shaft resistance and applying the residual toe resistances to the case of the Shamrock site. The results are shown in Fig. 11, which show an under prediction in each case though the general shape of the blow count with depth is reasonably represented, especially by the step-wise addition of the base stress up to $10 \%$ of the $\mathrm{q}_{\mathrm{c}}$ tip resistance. This analysis suggests that the addition of a residual base resistance component to the modified toe resistance profile provides an improved prediction of the blow counts. Overall, however, the modified IC-05 method with reduced shaft friction and unmodified base resistance seems to provide the most reliable method for estimating blow counts in the context that it mainly provides a conservative estimate in a driveability context, except for L09FA1 and L09FB1 where it under-predicts. The modified UWA-05 approach primarily under-predicts the blow counts for the given sites tested, though the addition of residual base stress reduces this under-prediction considerably in many cases.

Fig. 11. Predicted and recorded blow counts for Shamrock with residual added stress and modified base IC-05 method.

\section{Conclusions}

This paper examined the feasibility of applying both existing pile driveability approaches and modifying static capacity approaches to monopile foundations installed in North Sea sand. No single method investigated proved reliable for predicting blow counts across all the sites considered. For the traditional approaches, there is a tendency to underestimate the blows for sites with medium dense to dense sand. An exception being the use of the Stevens et al. plugged approach, which should not be applied for large diameter piles. The recommendation of using the lower bound prediction of the plugged case in dense sands applied for smaller diameter piles is clearly not suitable for monopiles.

Applying axial static capacity approaches (IC-05 \& UWA-05) in their raw unmodified form is mostly unsuitable for monopile driveability, with substantial overestimates frequently produced. This is particularly true for the UWA-05 approach, which vastly over-predicted blow counts in all cases. This is a result of the method taking an average base resistance (accounting for plugged behaviour during static loading) acting across the entire pile base area. The IC-05 approach over-predicts the blows for Skiff, Cutter and the upper layers of Caravel while providing a somewhat reasonable estimate for Caravel lower layers and Shamrock. The IC-05 approach generally under-predicted the blow counts at L09FA1 and L09FB1. Adopting the base settlement model in the UWA-05 approach provides a significant improvement, albeit the predictions tend to fall short of the recorded blow counts. The inclusion of potential residual base stresses of up to $10 \%$ of the $\mathrm{q}_{\mathrm{c}}$ value at a given depth gave a further improvement to the model that is keeping with field measurements, though still resulted in an underprediction in each case. The modifications applied, while not a formal method for predicting driveability, should certainly be considered as a guide in estimating the blow counts for monopiles. 
Comparisons between the monopiles and skirt pile are difficult to evaluate as only a single, isolated case was considered at Skiff. Overall, however, the IC-05 with modified shaft friction and the UWA05 with modifications including additional residual base stresses provided reasonable estimates of the blow counts for the cases considered, and would certainly provide an estimate of the expected behaviour of a monopile under driving to an acceptable industry tolerance. If adopted in tandem, they may provide an envelope of the expected response, with perhaps a tendency toward under-prediction as per L09FA1 and L09FB1. As with all approaches, engineering judgement should be taken when choosing a method and the analysis in this paper aims to highlight the potential disparity in predictions from the various available approaches.

The study undertaken in this paper has looked at the applicability of the various approaches to monopiles with diameters of $4.2 \mathrm{~m}$. A future study is recommended on larger diameter monopiles to further investigate the remaining uncertainties associated with these emerging geometries.

\section{Acknowledgements}

The authors wish to express their gratitude to Robert Overy and Shell UK for supplying records of the installations. Mainstream Renewable Power are also thanked for their support.

\section{References}

Aldridge, T.R., Carrington, T.M., Jardine, R.J., 2010. BP Clair phase 1-Pile driveability and capacity in extremely hard till. Front. Offshore Geotech. II 477.

Alm, T., Hamre, L., 2001. Soil model for pile driveability based on CPT interpretations, in: Proceedings of the 15th International Conference On Soil Mechanics and Foundation Engineering. Istanbul, Turkey, pp. 1297-1302.

API, 2007. API RP2A-WSD, Recommended Practice for Planning, Designing, and Constructing Fixed Offshore Platforms-Working Stress Design, American Petroleum Institute, Washington, DC.

Arany, L., Bhattacharya, S., Macdonald, J., Hogan, S.J., 2017. Design of monopiles for offshore wind turbines in 10 steps. Soil Dyn. Earthq. Eng. 92, 126-152. doi:10.1016/j.soildyn.2016.09.024

Byrne, T., Doherty, P., Gavin, K., Overy, R., 2012. Comparison of Pile Driveability Methods In North Sea Sand, in: Proc. 7th Intl Offshore Site Investigation and Geotechnics Conference: Integrated Geotechnologies - Present and Future. Society for Underwater Technology (SUT), London, UK, pp. 481-488.

Gavin, K., Igoe, D., Kirwan, L., 2013. The effect of ageing on the axial capacity of piles in sand. Proc. Inst. Civ. Eng. - Geotech. Eng. 166, 122-130.

Gavin, K., Jardine, R.J., Karlsrud, K., Lehane, B.M., 2015. The Effects of Pile Ageing on the Shaft Capacity of Offshore Piles in Sand, in: Proceedings of the International Symposium Frontiers in Offshore Geotechnics (ISFOG). Oslo.

Gavin, K.G., Lehane, B.M., 2007. Base Load-Displacement Response of Piles in Sand. Can. Geotech. J. 44, 1053-1063. 
Hirsch, T.J., Carr, L., Lowery, L.L., 1976. Pile Driving Analyses-Wave Equation User Manual. TTI Prog. Implement. Packag. I-IV.

Jamiolkowski, M., Ghionna, V.N., Lancellotta, R., Pasqualini, E., 1988. New Correlations of Penetration Tests for Design Practice, in: Penetration Testing 1988: Proceedings of the First International Symposium on Penetration Testing ISOPT-1. Orlando, FL.

Jardine, R., Standing, J., Chow, F., 2006. Some observations of the effects of time on the capacity of piles driven in sand. Geotechnique 55, 227-244.

Jardine, R.J., Chow, F.C., Overy, R.F., Standing, J., 2005. ICP Design Methods for Driven Piles in Sands and Clays. London.

Karlsrud, K., Jensen, T.G., Wensaas Lied, E.K., Nowacki, F., Simonsen, A.S., 2014. Significant ageing effects for axially loaded piles in sand and clay verified by new field load tests, in: Proceedings of the Offshore Technology Conference. Houston, Texas.

Kirwan, L., 2015. Investigation into Ageing Mechanisms for Axially Loaded Piles in Sand. University College Dublin.

Lambe, T.W., Whitman, R.V., 1969. Soil Mechanics. John Wiley \& Sons.

Lehane, B.M., Schneider, J.A., Xu, X., 2005. The UWA-05 method for prediction of axial capacity of driven piles in sand. Front. Offshore Geotech. ISFOG 683-689.

Overy, R., Sayer, P., 2007. The use of ICP design methods as a predictor of conductor drill-drive installation, in: Proceedings of the 6th International Offshore Site Investigation and Geotechnics Conference: Confronting New Challenges and Sharing Knowledge . Society for Underwater Technology (SUT), London, pp. 333-340.

Paik, K., Salgado, R., Lee, J., Kim, B., 2003. Behavior of Open- and Closed-Ended Piles Driven Into Sands. J. Geotech. Geoenvironmental Eng. 129.

Pile Dynamics, 2010. GRLWEAP Software.

Prendergast, L.J., Gavin, K., 2016. A comparison of initial stiffness formulations for small-strain soil - pile dynamic Winkler modelling. Soil Dyn. Earthq. Eng. 81, $27-41$. doi:10.1016/j.soildyn.2015.11.006

Prendergast, L.J., Hester, D., Gavin, K., O'Sullivan, J.J., 2013. An investigation of the changes in the natural frequency of a pile affected by scour. J. Sound Vib. 332, 6685-6702. doi:http://dx.doi.org/10.1016/j.jsv.2013.08.020i

Prendergast, L.J., Reale, C., Gavin, K., 2018. Probabilistic examination of the change in eigenfrequencies of an offshore wind turbine under progressive scour incorporating soil spatial variability. Mar. Struct. 57, 87-104. doi:10.1016/j.marstruc.2017.09.009

Robertson, P., 1990. Soil classification using the cone penetration test. Can. Geotech. J. 27, 151-158.

Schnaid, F., Lehane, B.M., Fahey, M., 2004. In situ test characterisation of unusual geomaterials, in: Proceedings of the International Conference of Site Characterisation. Porto, Portugal, pp. 49-73. 
670 Schneider, J., Harmon, I., 2010. Analyzing Drivability of Open Ended Piles in Very Dense Sands. J.

671 Deep Found. Inst. 4, 32-44.

672 Semple, R., Gemeinhardt, J., 1981. Stress history approach to analysis of soil resistance to pile driving, in: Offshore Technology Conference. Houston, USA.

Stevens, R., Wiltsie, E., Turton, T., 1982. Evaluating Drivability for Hard Clay, Very Dense Sand, and Rock, in: Offshore Technology Conference. Houston, USA.

Toolan, F.E., Fox, D.A., 1977. Geotechnical planning of piled foundations for offshore platforms. Proc. Inst. Civ. Eng. 62.

Wu, W.H., Prendergast, L.J., Gavin, K., 2018. An iterative method to infer distributed mass and stiffness profiles for use in reference dynamic beam-Winkler models of foundation piles from frequency response functions. J. Sound Vib. 431C, 1-19. 


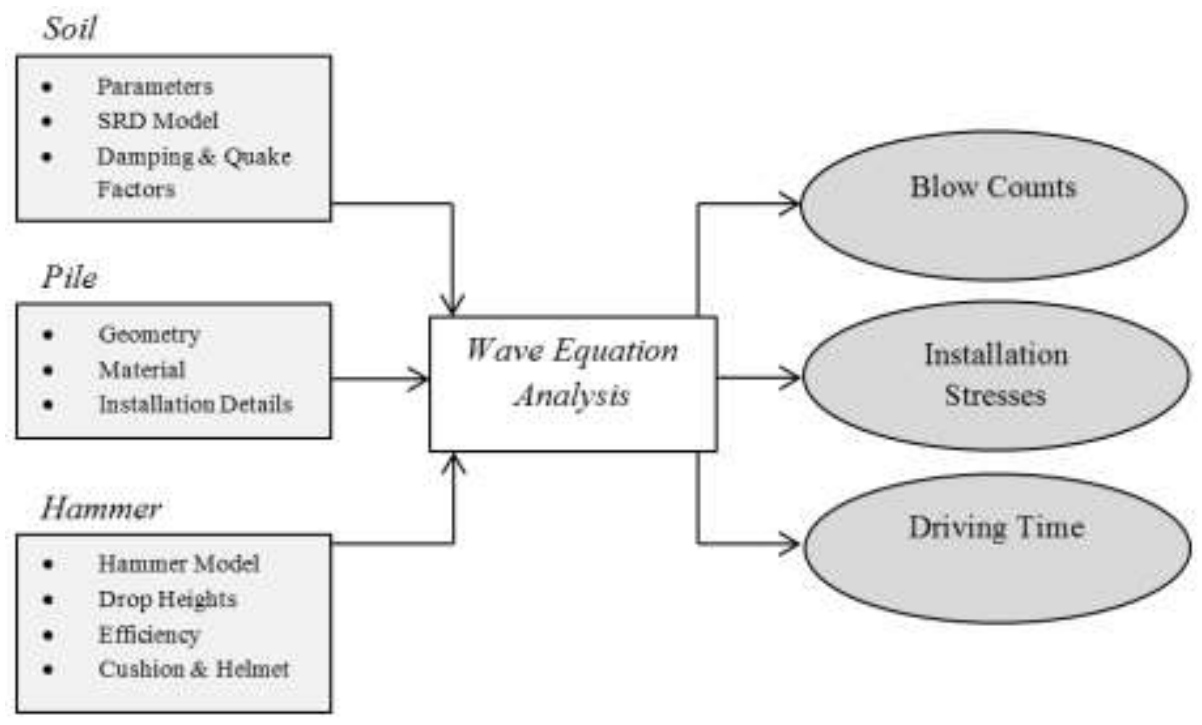

Fig. 1. Flow-chart of principal inputs and outputs available from a wave equation based driveability 684 analysis. 


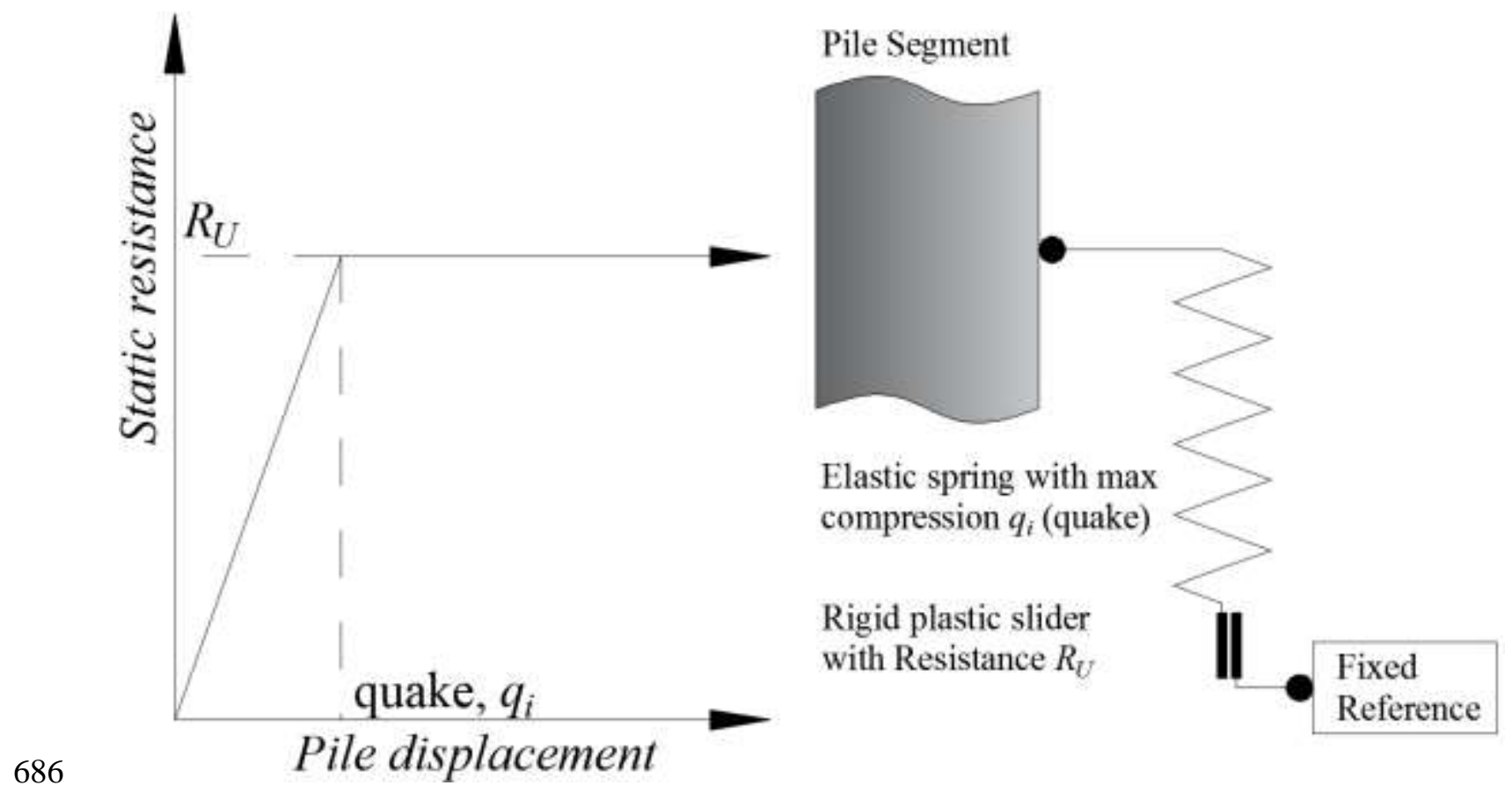

687

Fig. 2. Definition of quake

688 


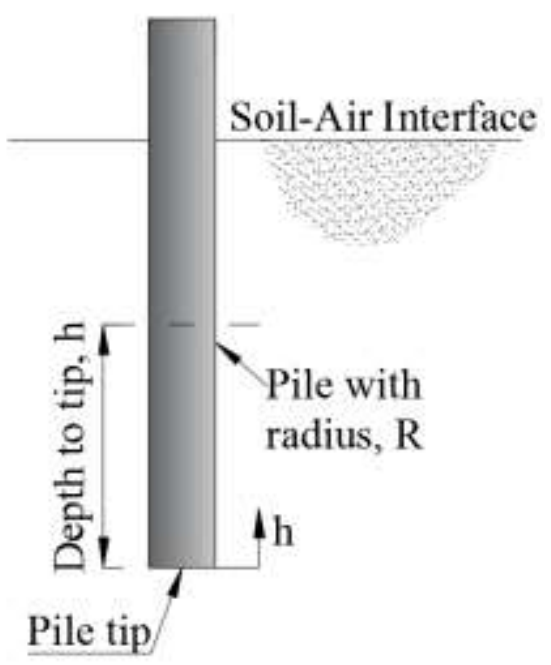




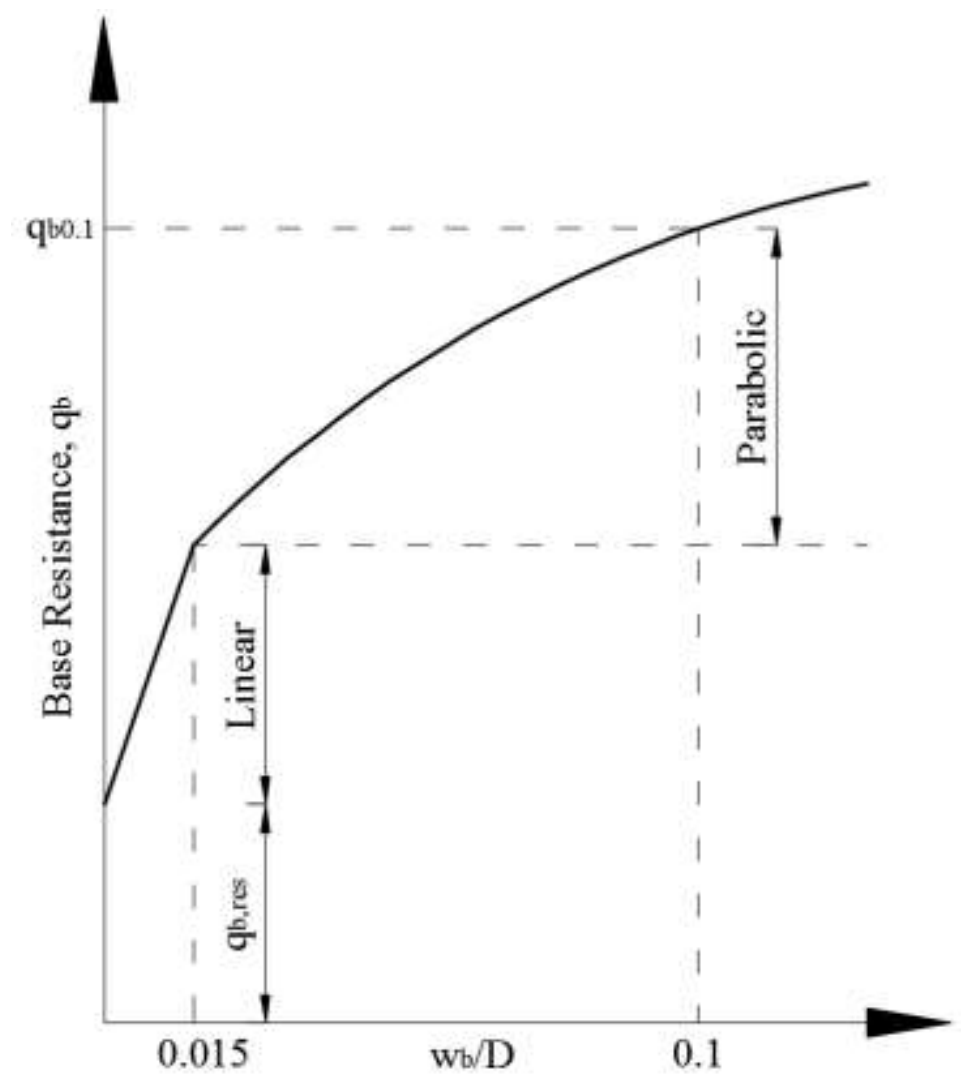

Fig. 4. Base resistance-settlement model 


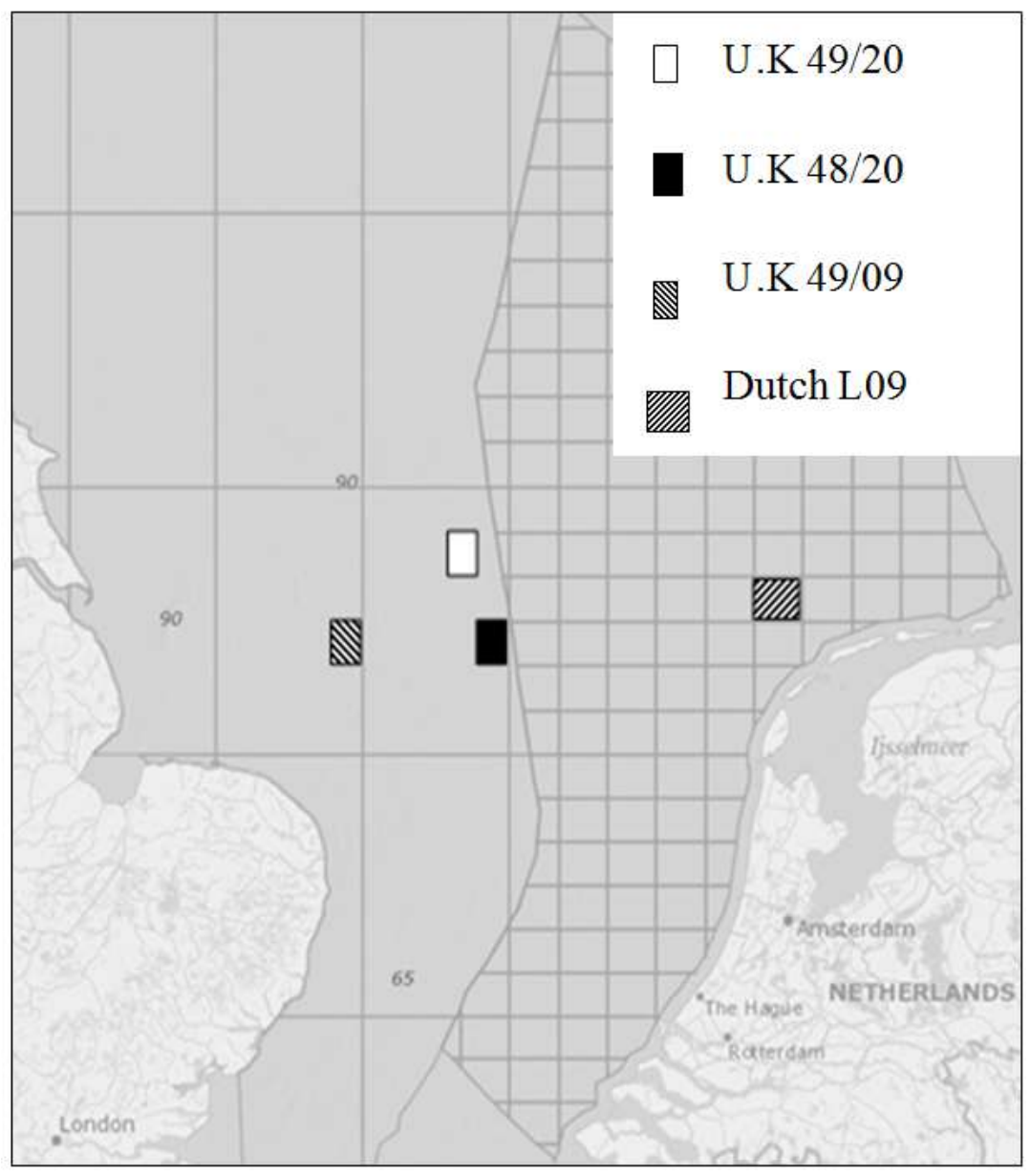

Fig. 5. Location map showing pile locations off Dutch and UK coasts. 


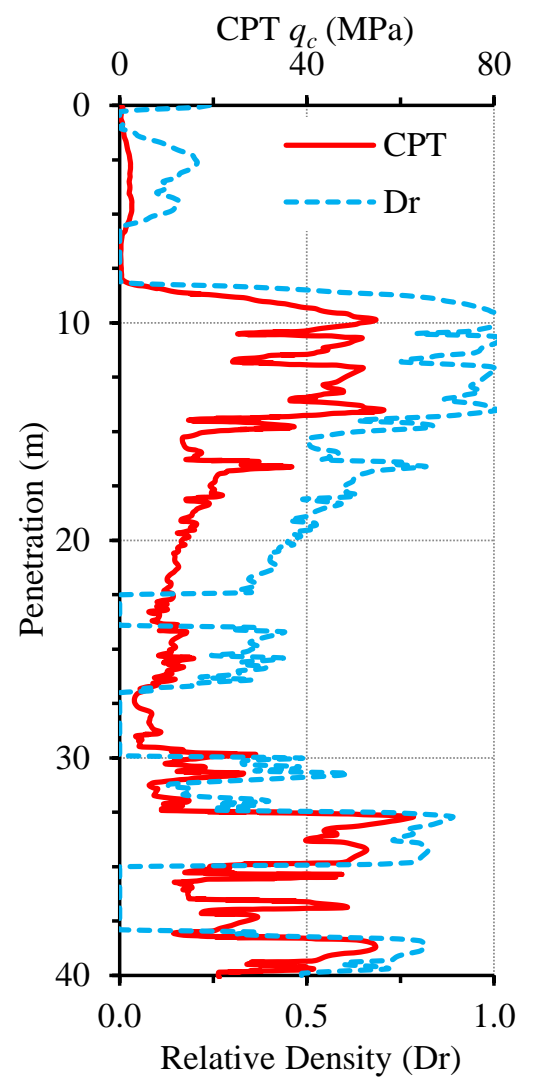

Fig. 6. Site CPT $q_{c}$ and Relative Density $\left(D_{r}\right)$ Profiles. (a) Caravel 


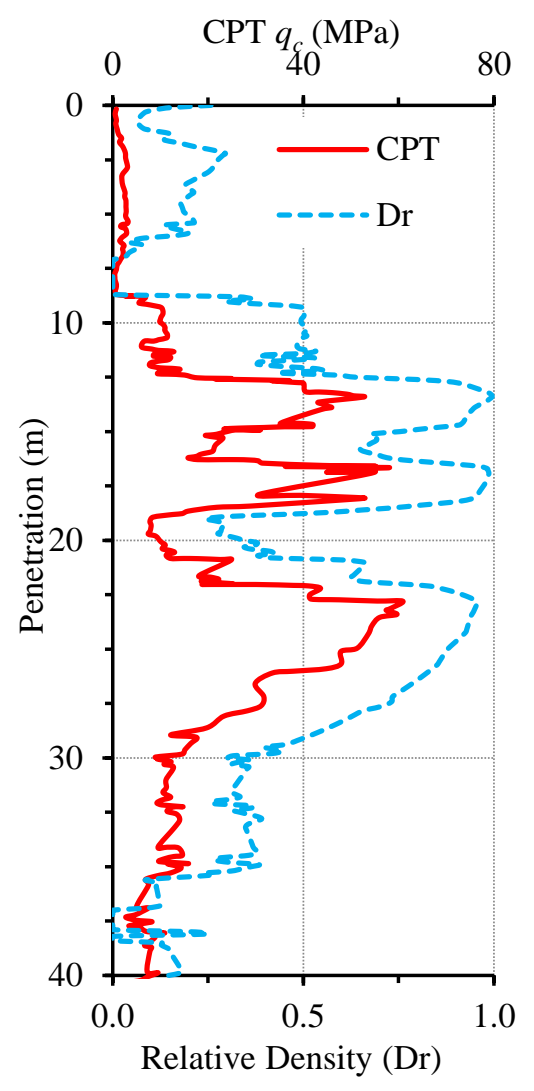

Fig. 6. Site CPT $\mathrm{q}_{\mathrm{c}}$ and Relative Density $\left(\mathrm{D}_{\mathrm{r}}\right)$ Profiles. (b) Shamrock 


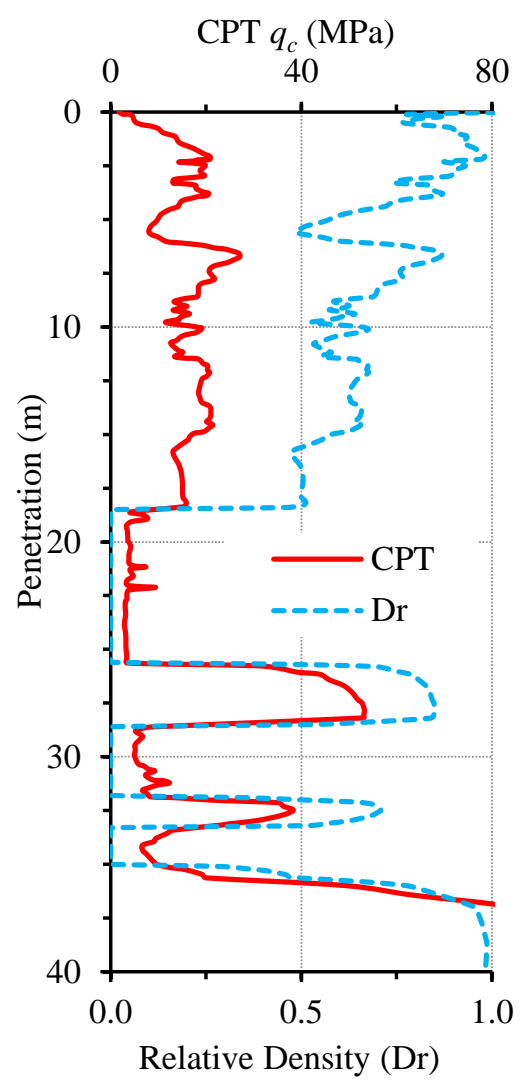

Fig. 6. Site CPT $\mathrm{q}_{\mathrm{c}}$ and Relative Density $\left(\mathrm{D}_{\mathrm{r}}\right)$ Profiles. (c) L09FB1 


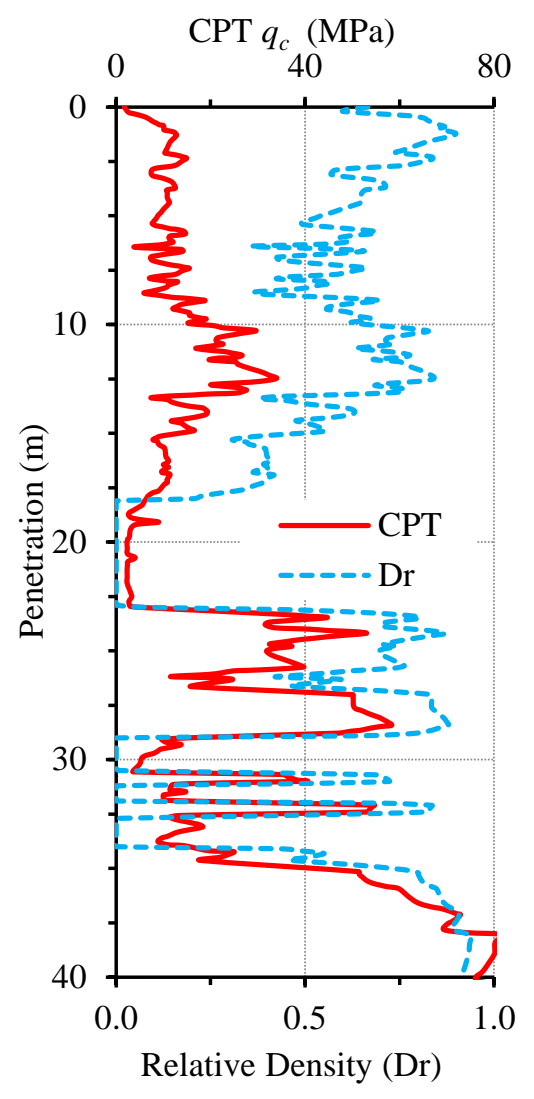

Fig. 6. Site CPT $\mathrm{q}_{\mathrm{c}}$ and Relative Density $\left(\mathrm{D}_{\mathrm{r}}\right)$ Profiles. (d) L09FA1 


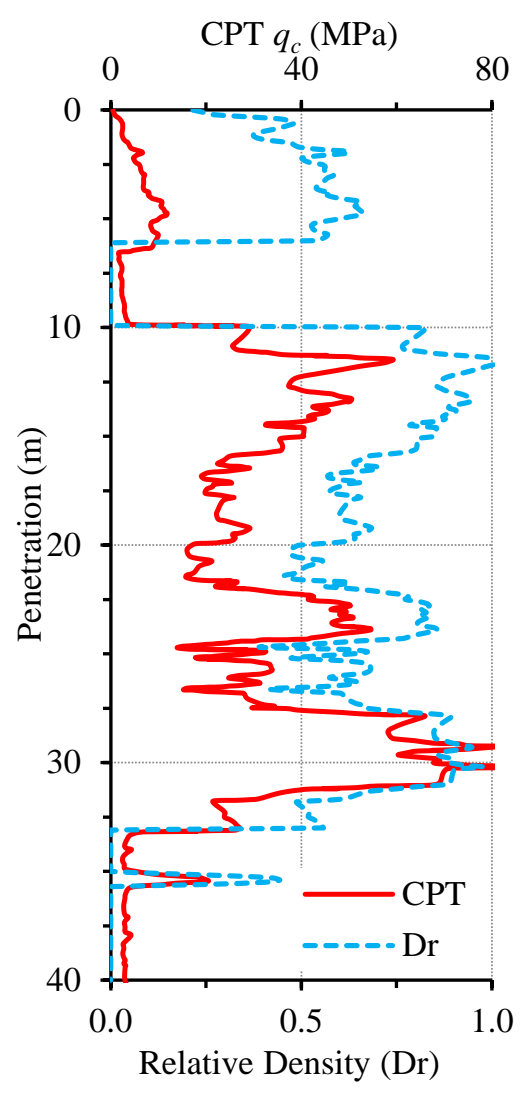

Fig. 6. Site CPT $\mathrm{q}_{\mathrm{c}}$ and Relative Density $\left(\mathrm{D}_{\mathrm{r}}\right)$ Profiles. (e) Cutter 


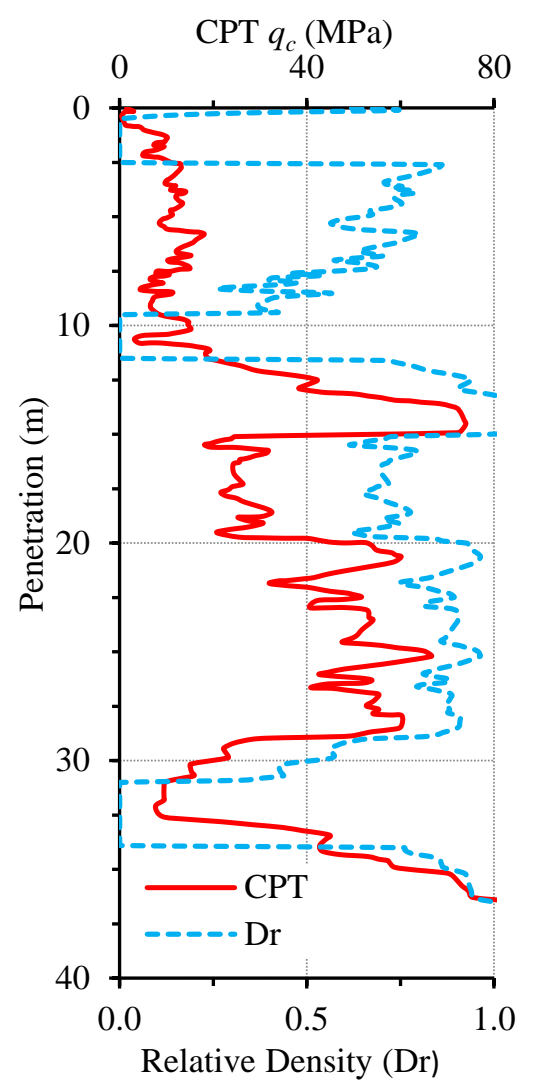

Fig. 6. Site CPT $\mathrm{q}_{\mathrm{c}}$ and Relative Density $\left(\mathrm{D}_{\mathrm{r}}\right)$ Profiles. (f) Skiff 


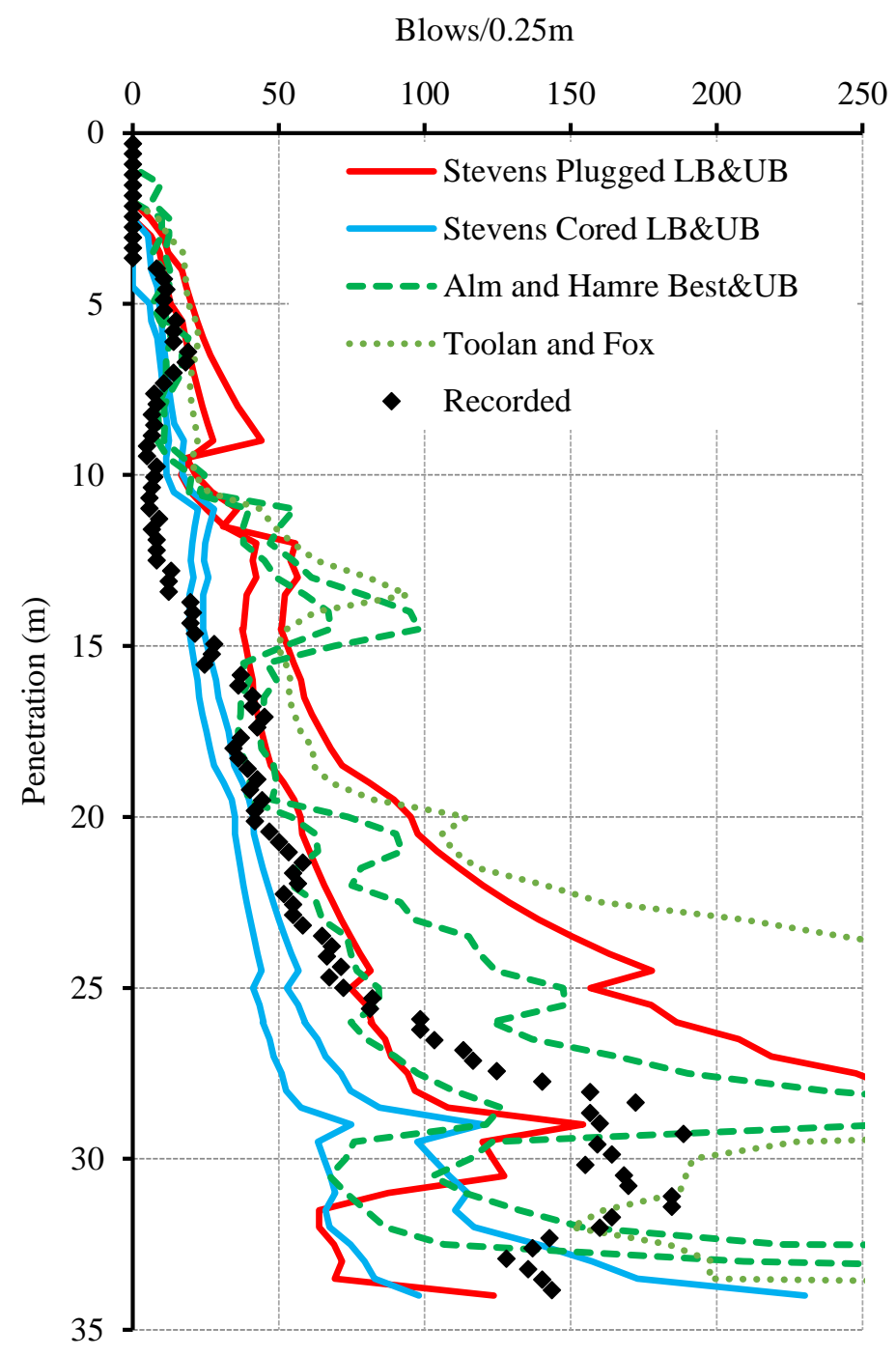

Fig. 7. Blow count predictions vs measured, (a) Skiff 


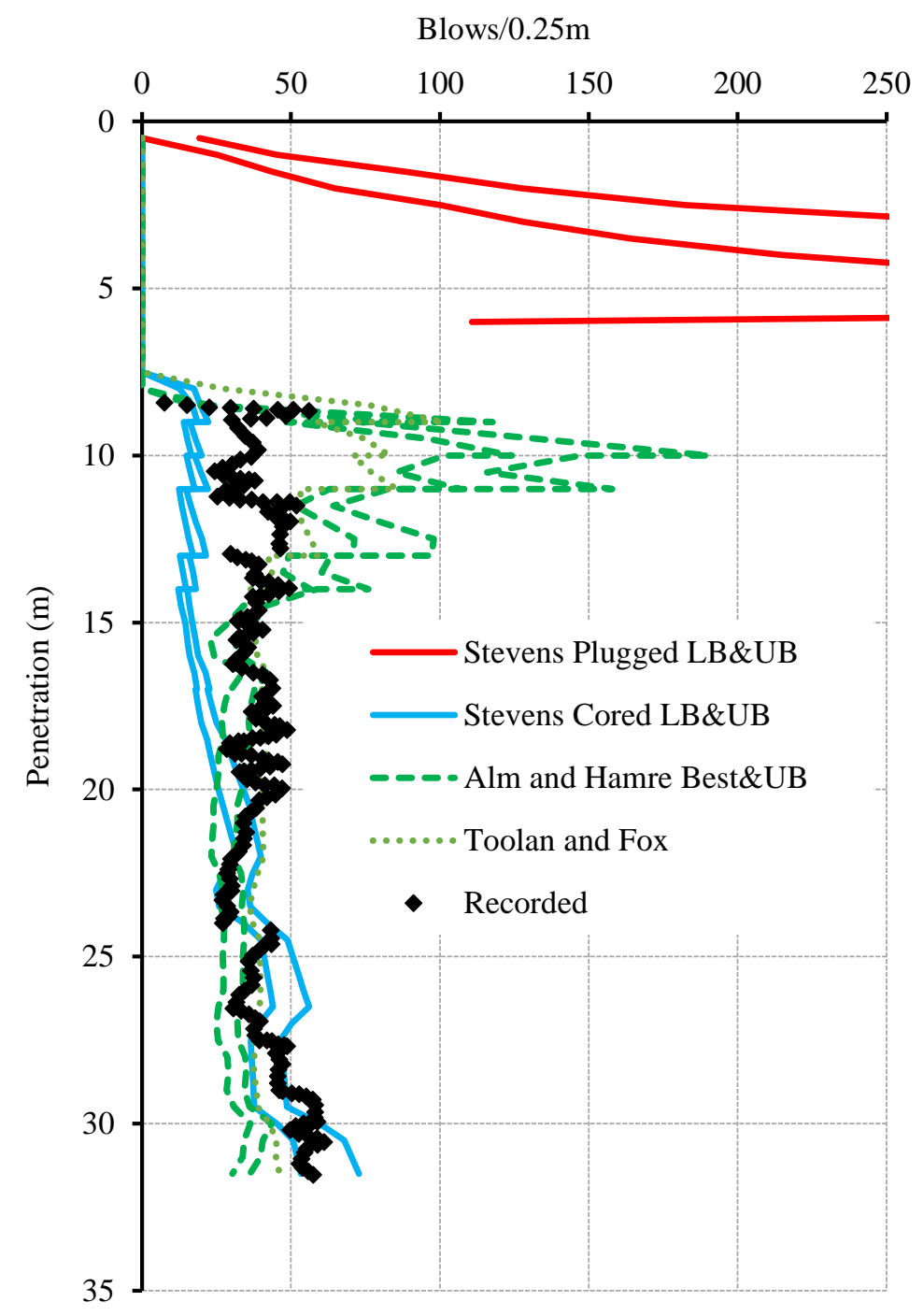

Fig. 7. Blow count predictions vs measured, (b) Caravel 


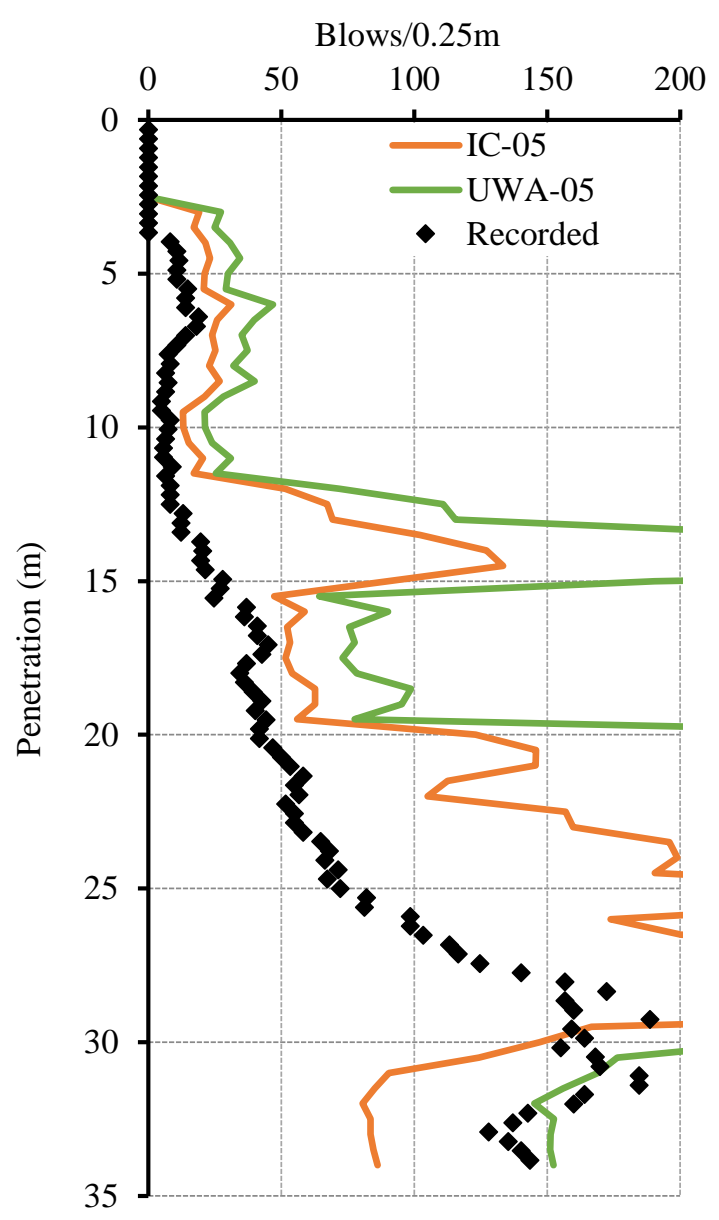

Fig. 8. Blow counts/ $0.25 \mathrm{~m}$ for all sites with unmodified CPT-based static capacity approaches (a) Skiff 


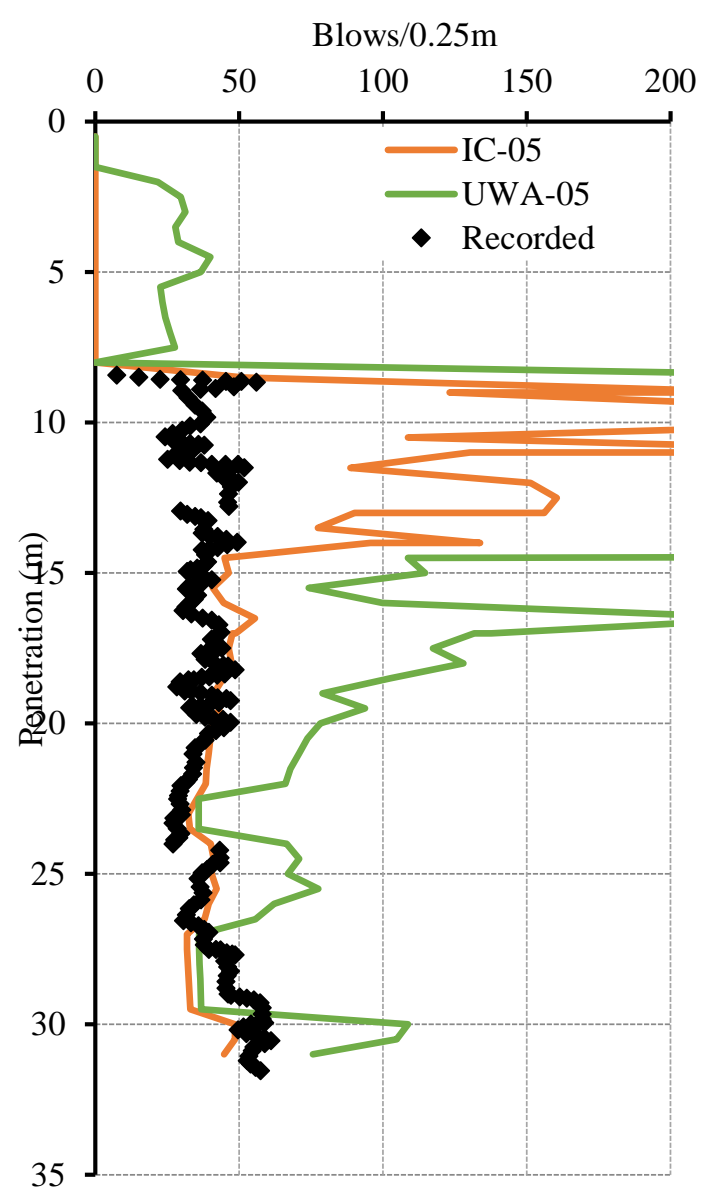

Fig. 8. Blow counts/ $0.25 \mathrm{~m}$ for all sites with unmodified CPT-based static capacity approaches (b) Caravel 


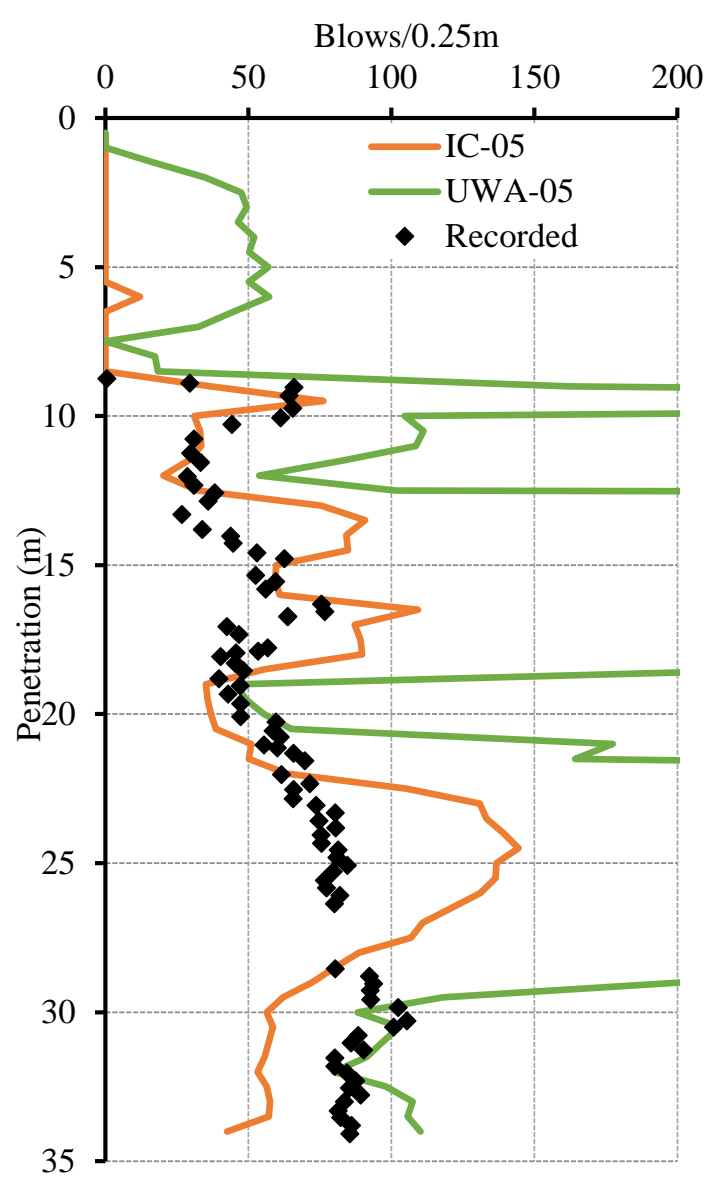

Fig. 8. Blow counts/ $0.25 \mathrm{~m}$ for all sites with unmodified CPT-based static capacity approaches (c) Shamrock 


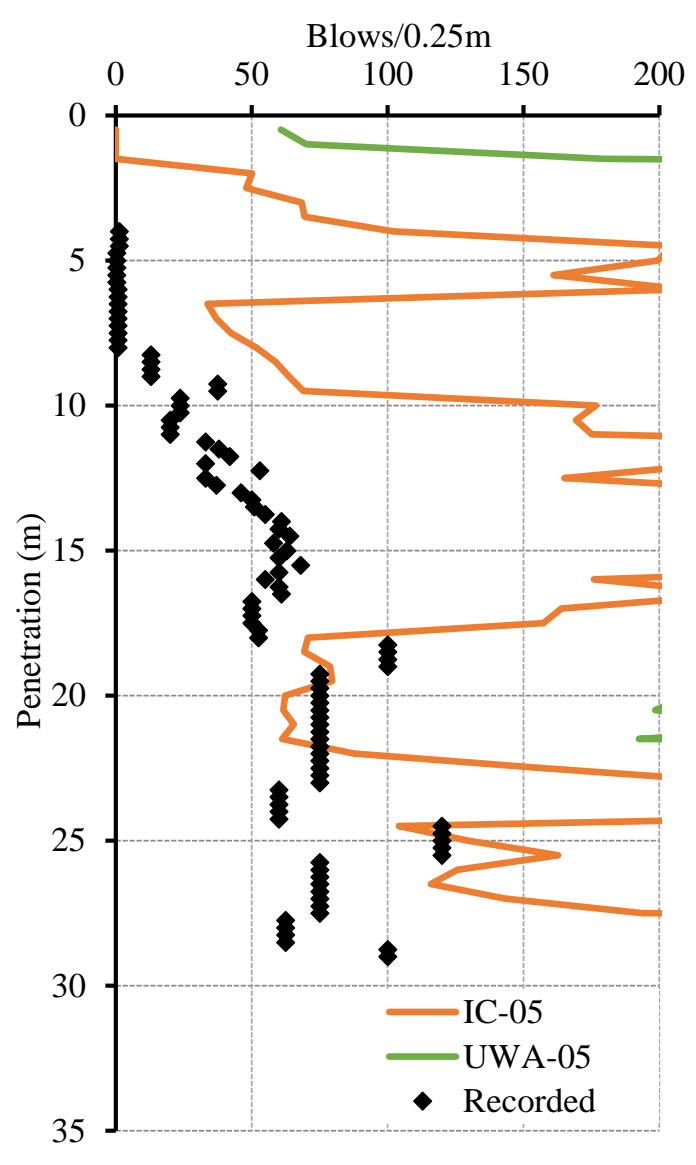

Fig. 8. Blow counts/ $0.25 \mathrm{~m}$ for all sites with unmodified CPT-based static capacity approaches (d) Cutter 


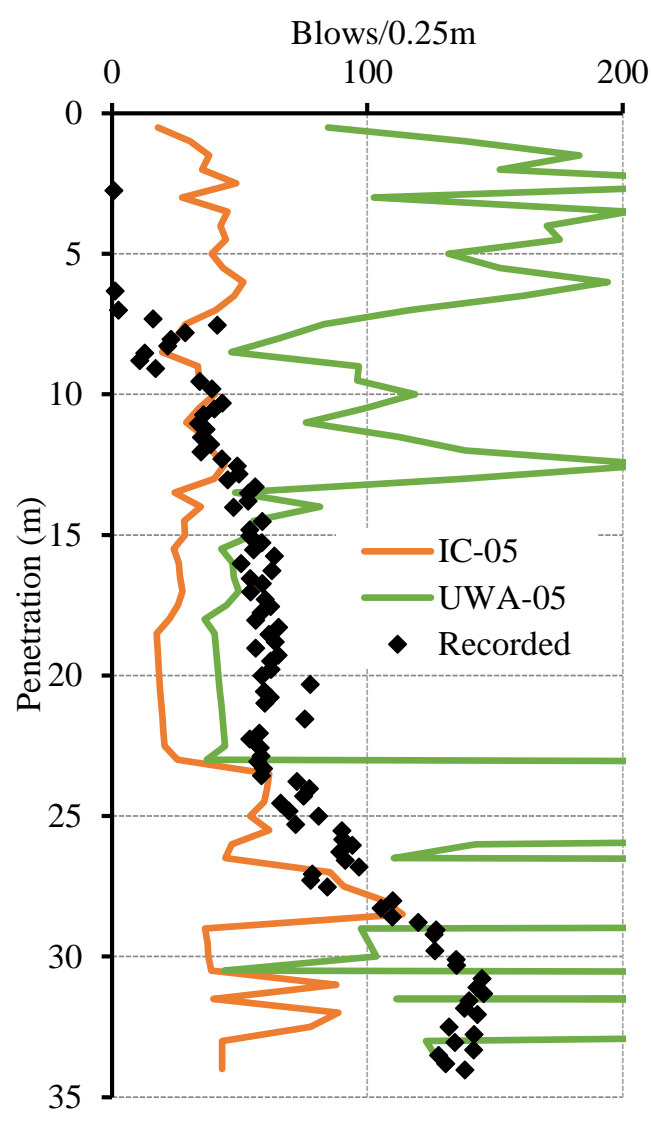

Fig. 8. Blow counts/ $0.25 \mathrm{~m}$ for all sites with unmodified CPT-based static capacity approaches (e) L09FA1 


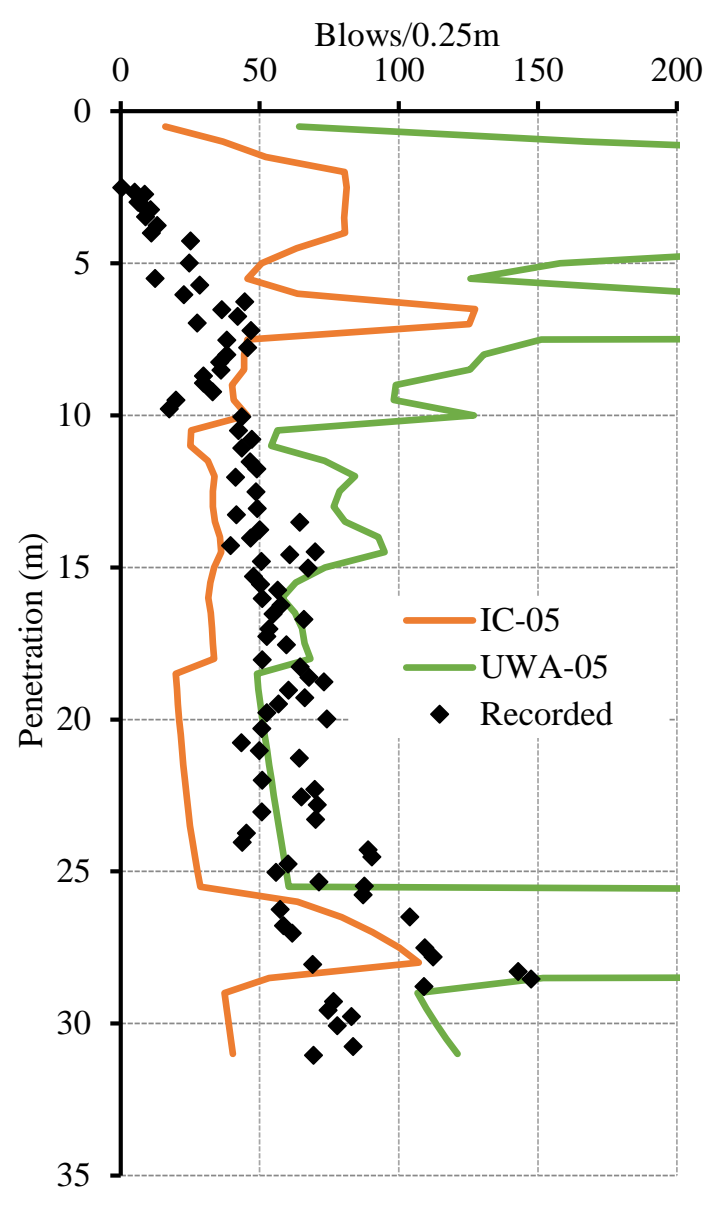

Fig. 8. Blow counts/ $0.25 \mathrm{~m}$ for all sites with unmodified CPT-based static capacity approaches (f) L09FB1 


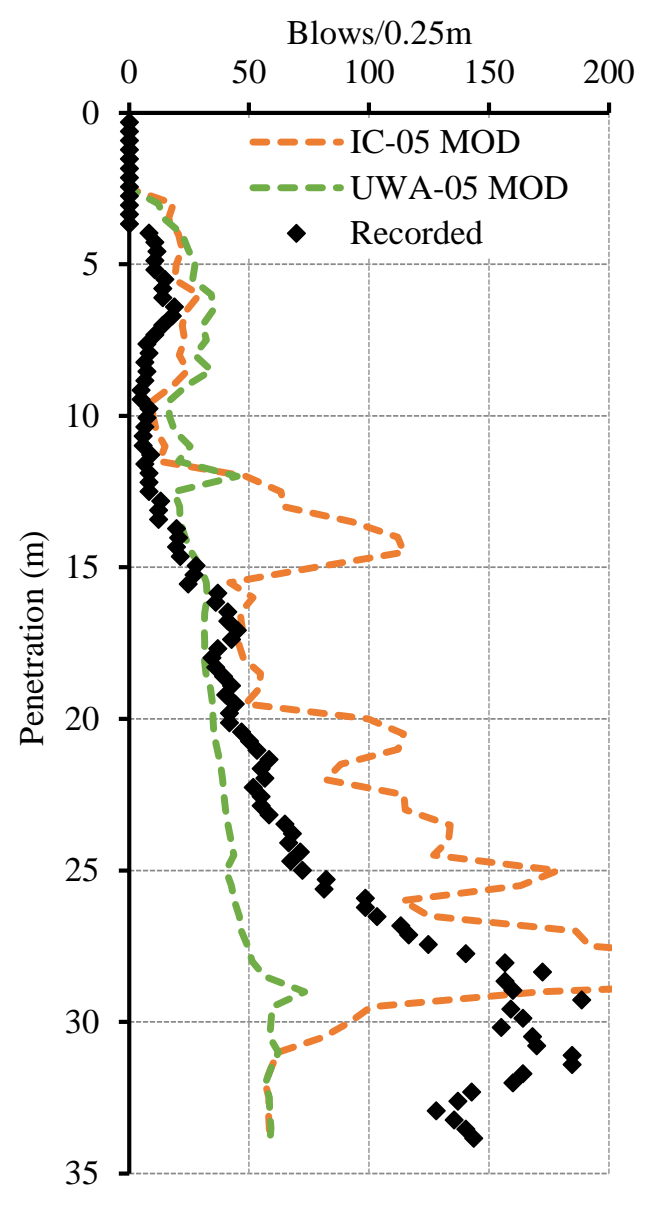

Fig. 9. Blow counts/ $0.25 \mathrm{~m}$ for all sites with modified CPT-based static capacity approaches (a) Skiff 


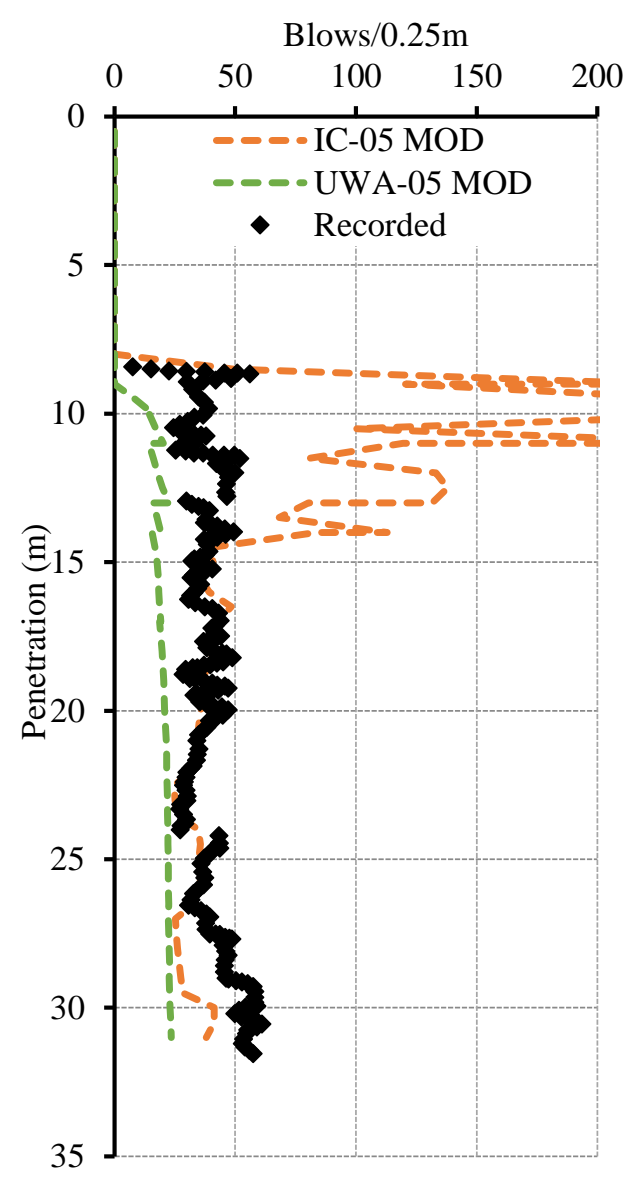

Fig. 9. Blow counts/ $0.25 \mathrm{~m}$ for all sites with modified CPT-based static capacity approaches (b) Caravel 


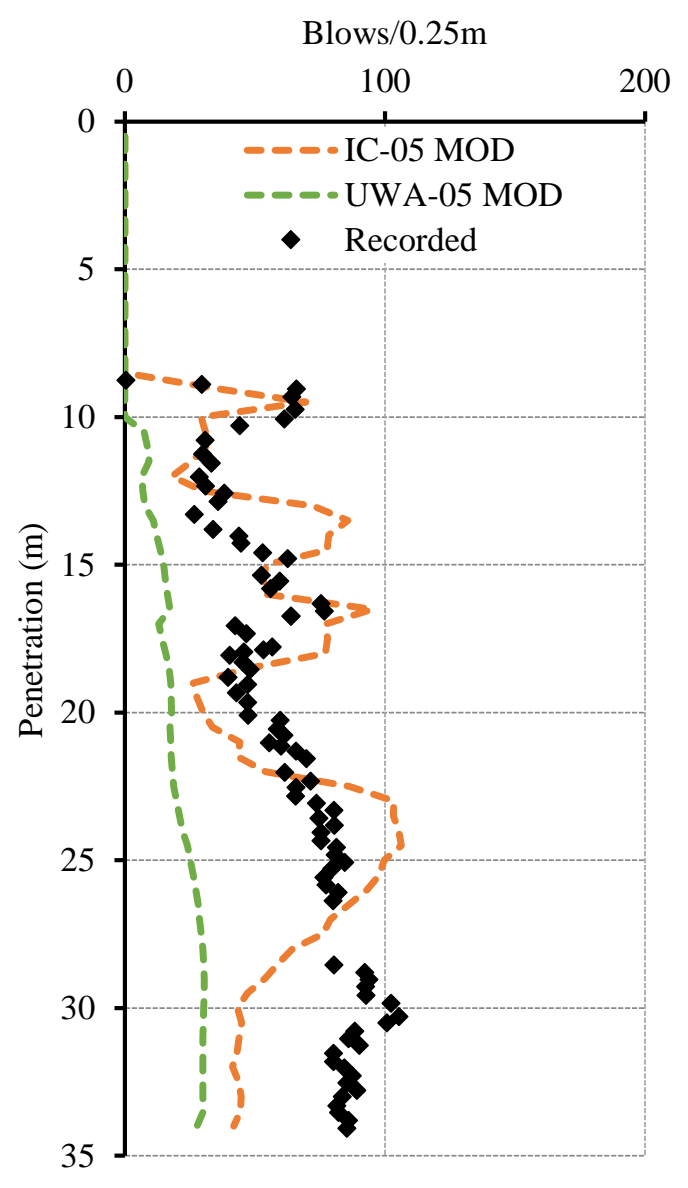

Fig. 9. Blow counts/ $0.25 \mathrm{~m}$ for all sites with modified CPT-based static capacity approaches (c) Shamrock 


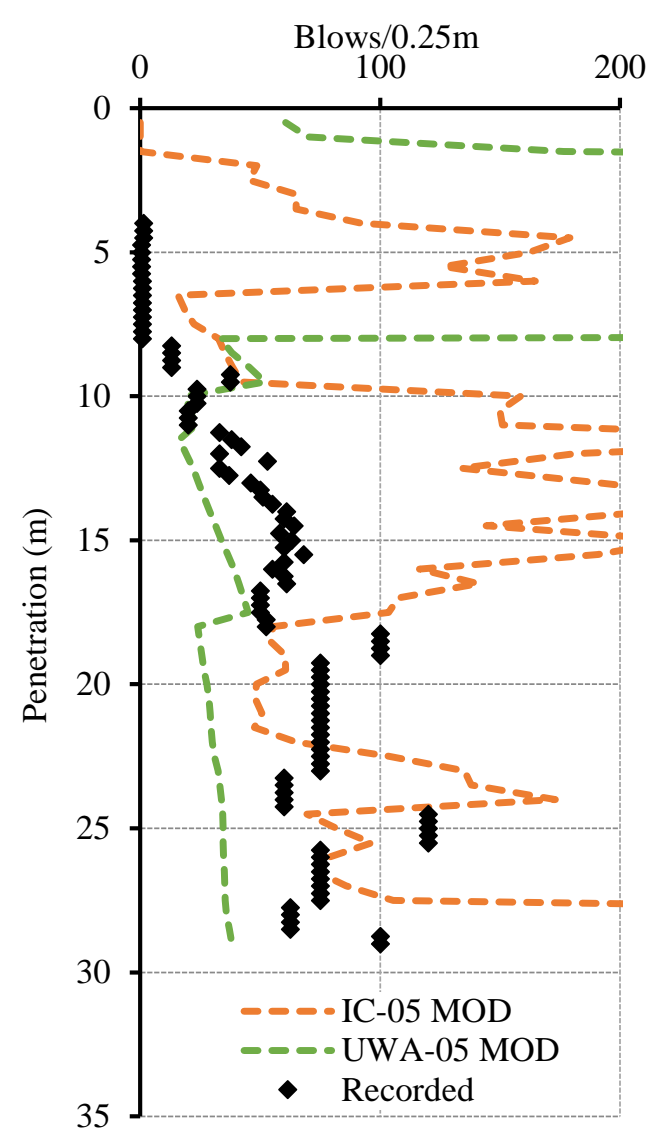

Fig. 9. Blow counts/ $0.25 \mathrm{~m}$ for all sites with modified CPT-based static capacity approaches (d) Cutter 


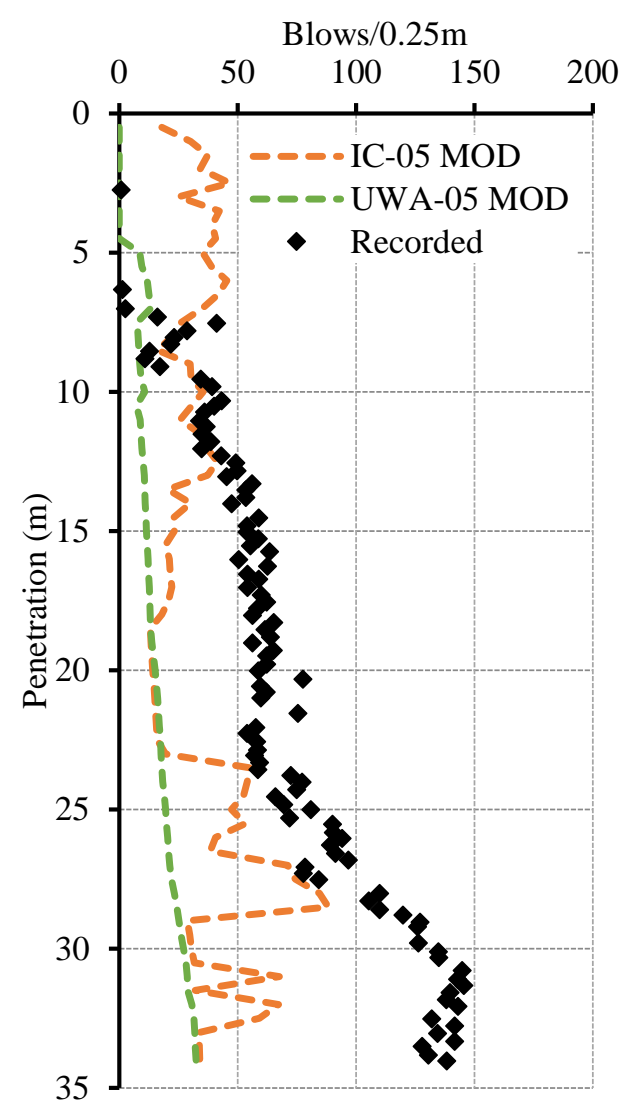

Fig. 9. Blow counts/ $0.25 \mathrm{~m}$ for all sites with modified CPT-based static capacity approaches (e) L09FA1 


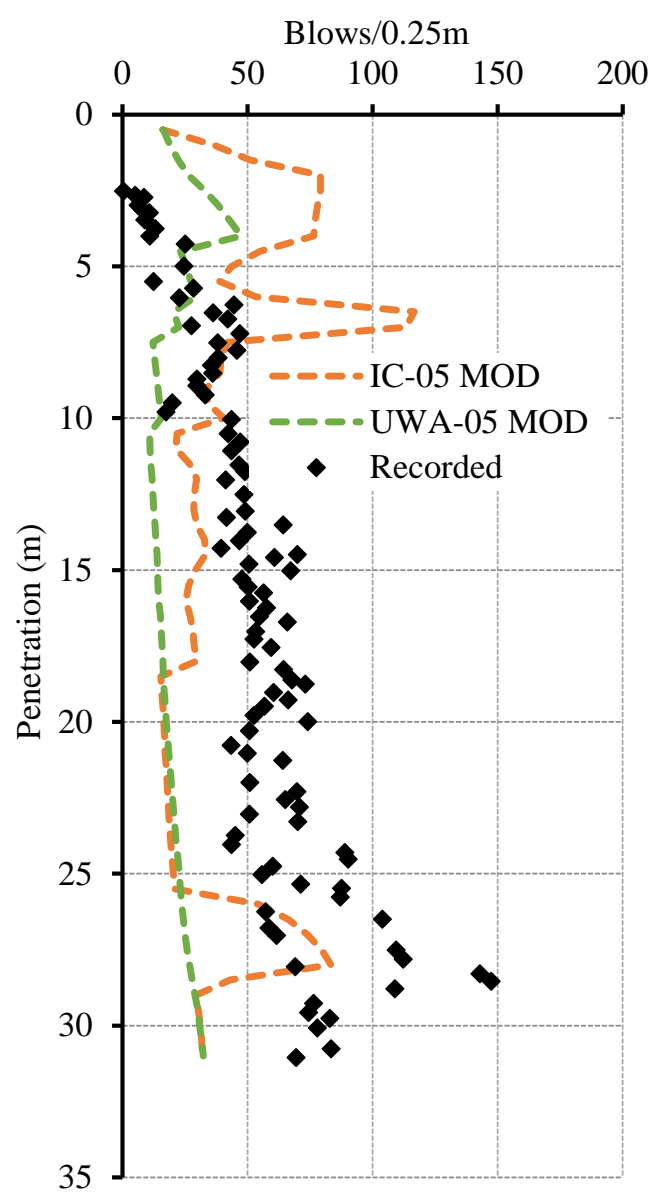

Fig. 9. Blow counts/ $0.25 \mathrm{~m}$ for all sites with modified CPT-based static capacity approaches (f) L09FB1 


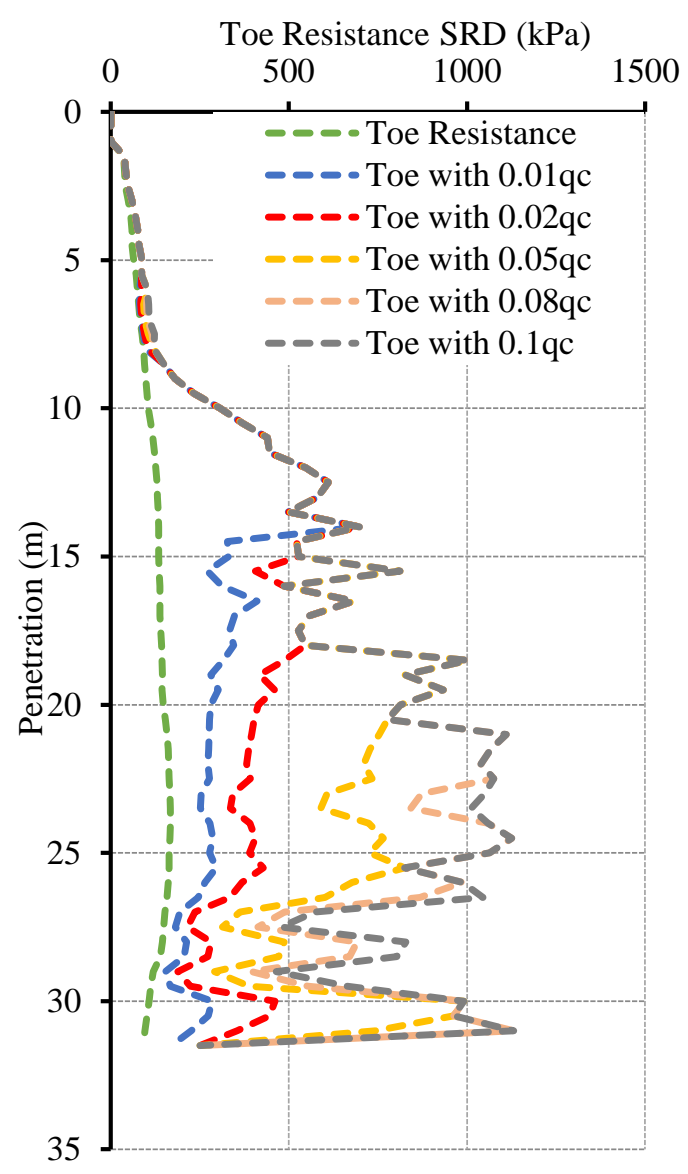

Fig. 10. Effect of residual base stress at Caravel site, (a) UWA modified toe resistance with varying residual stresses added 


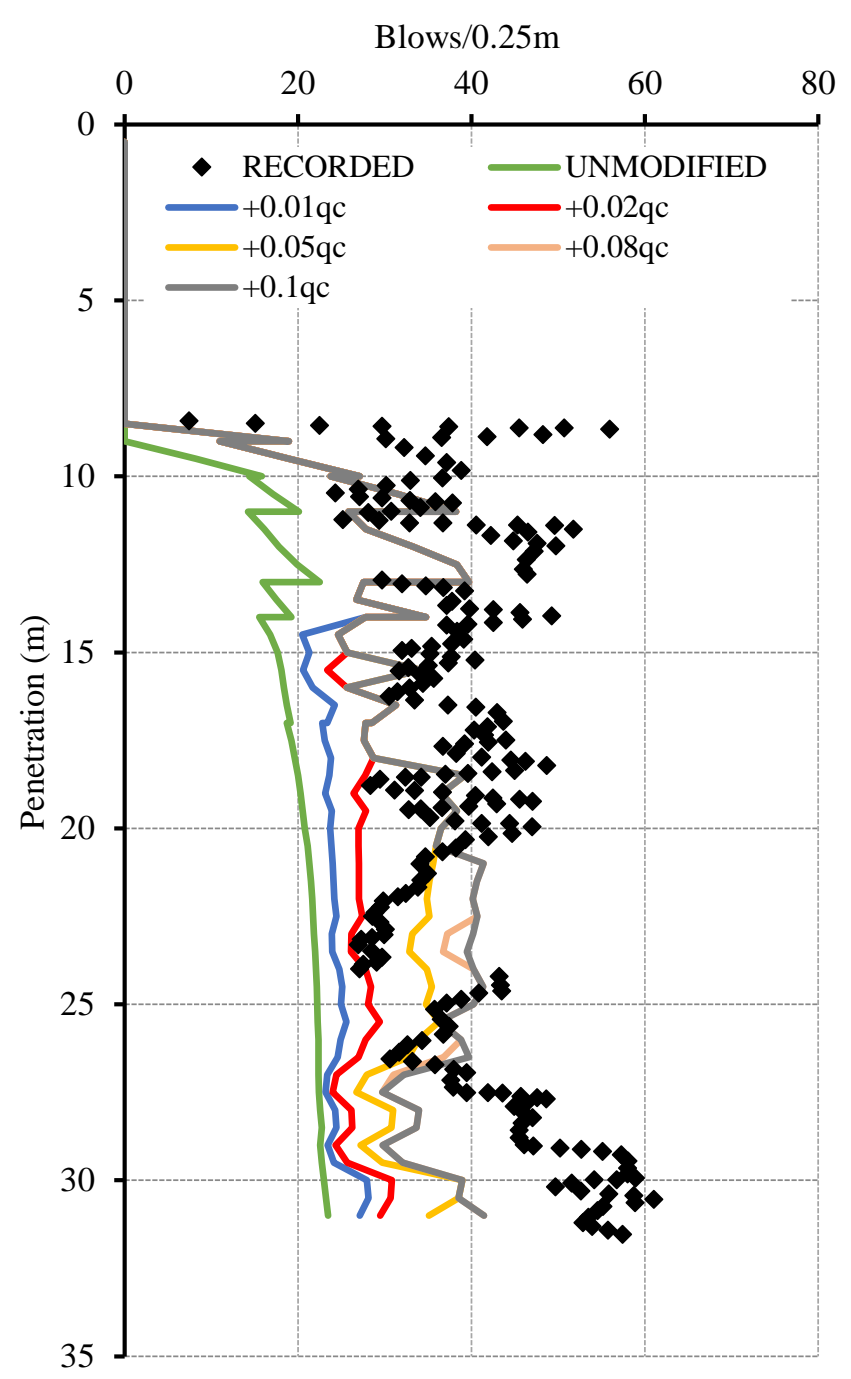

Fig. 10. Effect of residual base stress at Caravel site, (b) Predicted blow counts for a range of residual added stresses 


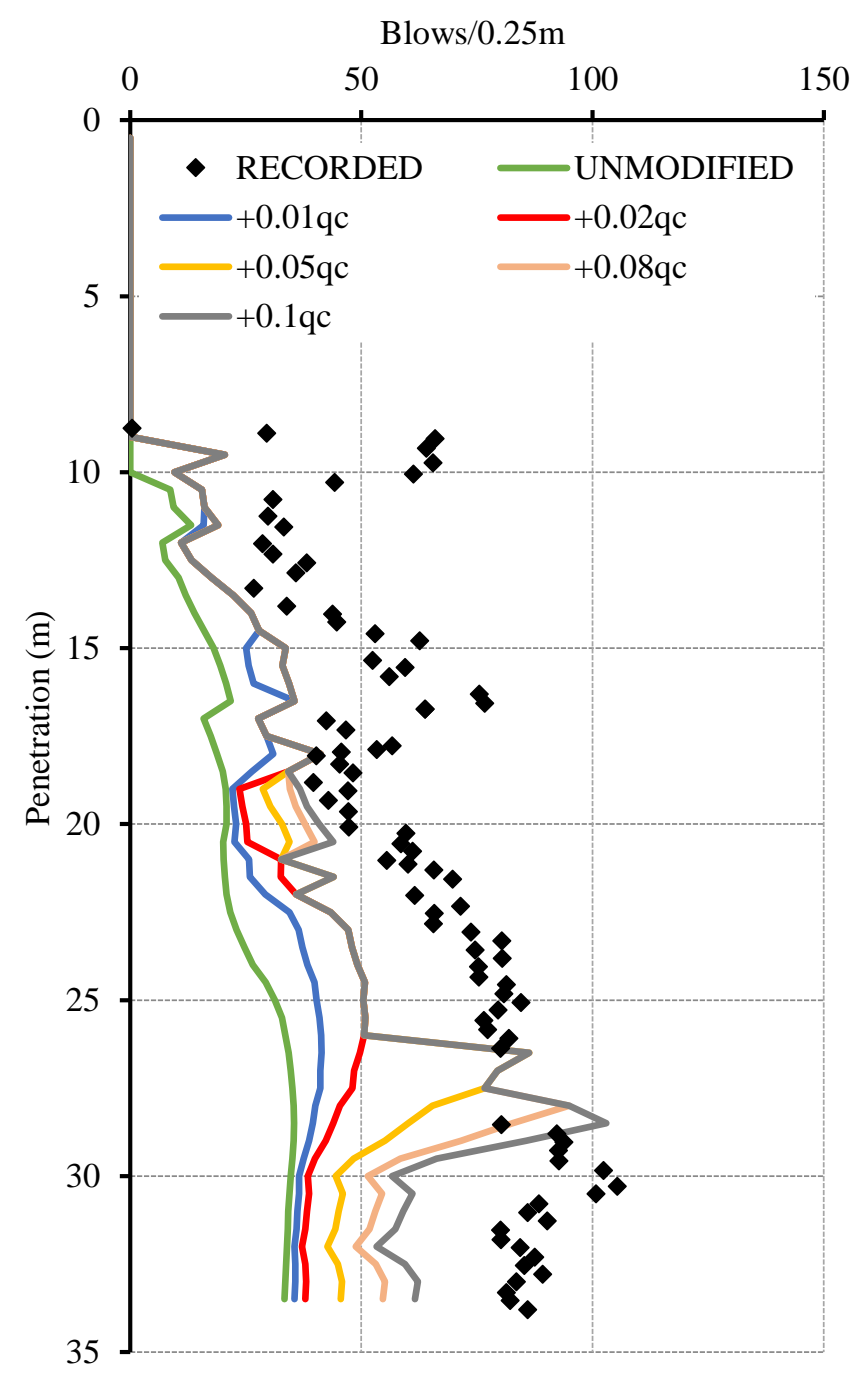

Fig. 11. Predicted and recorded blow counts for Shamrock with residual added stress and modified base IC-05 method. 
Table 1. Quake and damping values.

\begin{tabular}{|c|c|c|c|c|c|c|c|c|c|}
\hline \multirow{3}{*}{ Method } & \multicolumn{4}{|c|}{ Sand } & \multicolumn{4}{|c|}{ Clay } & \multirow{3}{*}{ Reference } \\
\hline & \multicolumn{2}{|c|}{$\begin{array}{c}\text { Quake } \\
(\mathbf{m m})\end{array}$} & \multicolumn{2}{|c|}{$\begin{array}{c}\text { Damping } \\
(\mathrm{s} / \mathrm{m})\end{array}$} & \multicolumn{2}{|c|}{$\begin{array}{c}\text { Quake } \\
(\mathrm{mm})\end{array}$} & \multicolumn{2}{|c|}{$\begin{array}{c}\text { Damping } \\
(\mathrm{s} / \mathrm{m})\end{array}$} & \\
\hline & Side & Toe & Side & Toe & Side & Toe & Side & Toe & \\
\hline $\begin{array}{l}\text { Alm and Hamre } \\
\text { (2001) }\end{array}$ & 2.5 & 2.5 & 0.25 & 0.5 & 2.5 & 2.5 & 0.25 & 0.5 & (Alm and Hamre, 2001) \\
\hline $\begin{array}{c}\text { Toolan and Fox } \\
\text { (1977) }\end{array}$ & 2.5 & 2.5 & 0.17 & 0.5 & 2.5 & 2.5 & 0.66 & 0.03 & (Hirsch et al., 1976) \\
\hline Stevens et al. (1982) & 2.5 & 2.5 & 0.27 & 0.5 & 2.5 & 2.5 & 0.1 & 0.5 & (Stevens et al., 1982) \\
\hline UWA (2005) & 2.5 & 2.5 & 0.25 & 0.5 & 2.5 & 2.5 & 0.65 & 0.5 & $\begin{array}{l}\text { (Schneider and Harmon, } \\
\text { 2010) }\end{array}$ \\
\hline IC (2005) & 2.5 & 2.5 & 0.16 & 0.5 & 2.5 & 2.5 & 0.65 & 0.5 & $\begin{array}{l}\text { GRLWEAP standard } \\
\text { values }\end{array}$ \\
\hline
\end{tabular}


Table 2. Site Description.

\begin{tabular}{|c|c|c|c|c|c|c|}
\hline & Caravel & Shamrock & L09FB1 & L09FA1 & Cutter & Skiff \\
\hline $\begin{array}{l}\text { North Sea } \\
\text { Location }\end{array}$ & UK 49/20 & UK 49/20 & Dutch L09 & Dutch L09 & UK 49/09 & UK 48/20 \\
\hline $\begin{array}{c}\text { Pile } \\
\text { Diameter } \\
(\mathbf{m})\end{array}$ & 4.2 & 4.2 & 4.2 & 4.2 & 4.2 & 0.762 \\
\hline $\begin{array}{c}\text { Wall } \\
\text { Thickness } \\
(\mathbf{m})\end{array}$ & $50 / 55 / 60$ & $50 / 60 / 70$ & $50 / 60$ & $50 / 60 / 65 / 70$ & $50 / 60$ & 38.1 \\
\hline $\begin{array}{c}\text { Pile } \\
\text { Length(m) }\end{array}$ & 40.5 & 43 & 40 & 43 & 41 & 41 \\
\hline $\begin{array}{c}\text { Penetration } \\
(\mathbf{m})\end{array}$ & 31.5 & 34 & 31 & 34 & 29 & 34 \\
\hline $\begin{array}{c}\text { Water } \\
\text { Depth }(\mathbf{m})\end{array}$ & 31 & 30 & 22 & 23.5 & 32 & 26 \\
\hline Hammer & MHU-600 & MHU-600 & MHU-600 & MHU-600 & IHC S-600 & IHC S-90 \\
\hline $\begin{array}{l}\text { Dominant } \\
\text { Soil } \\
\text { Conditions }\end{array}$ & $\begin{array}{l}\text { LOOSE } \\
\text { SAND } \\
\text { initially, } \\
\text { MED } \\
\text { DENSE - } \\
\text { VERY } \\
\text { DENSE } \\
\text { fine to } \\
\text { medium } \\
\text { SAND } \\
\text { below 8m } \\
\text { with clay } \\
\text { layers }\end{array}$ & $\begin{array}{l}\text { LOOSE } \\
\text { SAND } \\
\text { initially, } \\
\text { MED } \\
\text { DENSE - } \\
\text { VERY } \\
\text { DENSE } \\
\text { slightly } \\
\text { silty SAND } \\
\text { below 8.5m } \\
\text { with clay } \\
\text { layers }\end{array}$ & $\begin{array}{l}\text { DENSE } \\
\text { VERY } \\
\text { DENSE } \\
\text { silica fine } \\
\text { to medium } \\
\text { SAND with } \\
\text { Stiff - Hard } \\
\text { clay layers } \\
\text { present }\end{array}$ & $\begin{array}{l}\text { DENSE } \\
\text { VERY } \\
\text { DENSE } \\
\text { silica fine to } \\
\text { medium } \\
\text { SAND with } \\
\text { Stiff - Hard } \\
\text { clay layers } \\
\text { present }\end{array}$ & $\begin{array}{c}\text { MED } \\
\text { DENSE - } \\
\text { VERY } \\
\text { DENSE } \\
\text { fine to } \\
\text { medium } \\
\text { SAND with } \\
\text { shell } \\
\text { fragments, } \\
\text { clay layers } \\
\text { present }\end{array}$ & $\begin{array}{l}\text { DENSE - } \\
\text { VERY } \\
\text { DENSE } \\
\text { fine to } \\
\text { medium } \\
\text { SAND with } \\
\text { Stiff clay } \\
\text { layers } \\
\text { present }\end{array}$ \\
\hline $\begin{array}{c}\text { Sand } \\
\text { Friction } \\
\text { Angles } \\
\text { (Direct } \\
\text { Shear: } \\
\text { Soil-Steel) }\end{array}$ & $28^{\circ}-30^{\circ}$ & $27^{\circ}-30^{\circ}$ & $29^{\circ}-31^{\circ}$ & $26^{\circ}-30^{\circ}$ & $28^{\circ}-30^{\circ}$ & $28^{\circ}-31^{\circ}$ \\
\hline $\begin{array}{c}\text { Clay Layer } \\
\mathbf{S}_{\mathbf{u}}(\mathbf{k P a})\end{array}$ & $150-400$ & $30-100$ & $175-300$ & $100-300$ & $75-175$ & $50-400$ \\
\hline
\end{tabular}


Table 3. Relative Density $\left(\mathrm{D}_{\mathrm{r}}\right)$ definitions (Lambe and Whitman, 1969)

\begin{tabular}{cc}
\hline Consistency & Relative Density $\mathbf{D}_{\mathbf{r}}(\boldsymbol{\%})$ \\
\hline Very Loose & $0-15$ \\
Loose & $15-35$ \\
Medium Dense & $35-65$ \\
Dense & $65-85$ \\
Very Dense & $85-100$ \\
\hline
\end{tabular}


Table 4.Total blow-counts measured and predicted for Skiff and Caravel

\begin{tabular}{|c|c|c|c|c|c|c|c|c|c|}
\hline & & $\begin{array}{l}\text { Recorde } \\
\text { d }\end{array}$ & $\begin{array}{l}\text { Steven } \\
\text { s } \\
\text { Plugge } \\
\text { d LB }\end{array}$ & $\begin{array}{l}\text { Steven } \\
\text { s } \\
\text { Plugge } \\
\text { d UB }\end{array}$ & $\begin{array}{l}\text { Steven } \\
\text { s } \\
\text { Cored } \\
\text { LB }\end{array}$ & $\begin{array}{l}\text { Steven } \\
\text { s } \\
\text { Cored } \\
\text { UB }\end{array}$ & $\begin{array}{l}\text { A\& } \\
\text { H } \\
\text { Best }\end{array}$ & $\begin{array}{l}\text { A\&H } \\
\text { Upper }\end{array}$ & $\mathbf{T \& F}$ \\
\hline \multirow[t]{2}{*}{ Skiff } & $\begin{array}{l}\text { Total } \\
\text { Blowcoun } \\
\text { ts }\end{array}$ & 6729 & 3609 & 5667 & 2188 & 3271 & 4405 & 5147 & 9157 \\
\hline & Notes & - & - & $\begin{array}{l}\text { Refuse } \\
\mathrm{s} \quad \text { at } \\
29 \mathrm{~m}\end{array}$ & - & - & - & $\begin{array}{l}\text { Refuse } \\
\mathrm{s} \quad \text { at } \\
33 \mathrm{~m}\end{array}$ & $\begin{array}{l}\text { Refuse } \\
\mathrm{s} \quad \text { at } \\
33.5 \mathrm{~m}\end{array}$ \\
\hline \multirow[t]{2}{*}{$\begin{array}{l}\text { Carav } \\
\text { el }\end{array}$} & $\begin{array}{l}\text { Total } \\
\text { Blowcoun } \\
\text { ts }\end{array}$ & 3635 & - & - & 1383 & 1761 & 2180 & 2904 & 2533 \\
\hline & Notes & - & $\begin{array}{l}\text { Refuse } \\
\mathrm{s}\end{array}$ & $\begin{array}{l}\text { Refuse } \\
\mathrm{s}\end{array}$ & - & - & - & - & - \\
\hline
\end{tabular}

